\title{
Study of structure and spectroscopy of water-hydroxide ion clusters: A combined simulated annealing and DFT-based approach
}

\author{
SATYAJIT GUHA, SOUMYA GANGULY NEOGI and PINAKI CHAUDHURY* \\ Department of Chemistry, University of Calcutta, 92, APC Road, Kolkata 700 009, India \\ e-mail: pinakc@rediffmail.com
}

MS received 7 June 2013; revised 18 November 2013; accepted 4 December 2013

\begin{abstract}
In this paper, we explore the use of stochastic optimizer, namely simulated annealing (SA) followed by density function theory (DFT)-based strategy for evaluating the structure and infrared spectroscopy of $\left(\mathrm{H}_{2} \mathrm{O}\right)_{n} \mathrm{OH}^{-}$clusters where $n=1-6$. We have shown that the use of SA can generate both global and local structures of these cluster systems. We also perform a DFT calculation, using the optimized coordinate obtained from SA as input and extract the IR spectra of these systems. Finally, we compare our results with available theoretical and experimental data. There is a close correspondence between the computed frequencies from our theoretical study and available experimental data. To further aid in understanding the details of the hydrogen bonds formed, we performed atoms in molecules calculation on all the global minimum structures to evaluate relevant electron densities and critical points.
\end{abstract}

Keywords. Simulated annealing; density function theory; water clusters; infrared spectrum.

\section{Introduction}

Cluster chemistry and physics have become an actively pursued area of research in contemporary chemical physics. Both atomic and molecular clusters are studied and characterized with great effort. Experimentalists are interested in determining the bonding, ${ }^{1-18}$ structure and spectroscopy of these systems and theoreticians have contributed to the logical explanation of experimental findings. There are different types of systems ranging from atomic clusters, especially noble gas clusters (modelled by Lennard Jones (LJ) potential), metallic and alloy clusters (modelled by Gupta potential) and molecular clusters, especially water clusters (modelled by ST2, SPC, TIP2P, BF, TIPS2, TIP3P, TIP4P, SPCE/POL, etc.) and hydrated halide ion clusters (modelled by modified TIP3P, TIP4P, SPCE/POL, etc.), which are studied extensively by different researchers. ${ }^{19-40}$ These potentials are a combination of Lennard-Jones and Coulombic interactions with the contribution of polarizability factors. Besides these model potentials, theoreticians have also used brute force $a b$ initio based quantum chemical calculations using DFT, MP2, etc. on these systems. ${ }^{41-96}$ Still the size-specific water-hydroxide ion clusters where water encapsulates a single hydroxide

\footnotetext{
*For correspondence
}

ion is an interesting system and a principal subject for molecular dynamics and statistical mechanical simulations.

The study of these cluster systems using the above mentioned empirical potentials is difficult because the potential energy surface (PES) of these systems is extremely rugged and supports multiple minima. The task of finding the global or the deeper minima in these systems is challenging and can be a serious test of different optimization techniques. In scenarios such as these, it is prudent to switch over to stochastic optimization techniques against conventional deterministic ones. The reason is obvious. Stochastic techniques have a greater potential of finding global minimum than deterministic ones. Simulated annealing $(\mathrm{SA})^{97-117}$ is one such celebrated scheme and has been widely used in contemporary chemical studies and can be a good choice for studying hydrogen bonded ${ }^{118-122}$ cluster systems of the type $\left(\mathrm{H}_{2} \mathrm{O}\right)_{n} \mathrm{OH}^{-}$as shown by us.

The motivation for studying these systems is manifold. The most obvious is to see how competing hydrogen bonds and their relative strengths dictate the final structure that a cluster such as these can have. The generation of size specific clusters and the characterization of the $\mathrm{O}-\mathrm{H}$ stretching frequencies for water molecules coordinating hydroxide ion as well as its variation with the size of the cluster is an engaging area of research. If the central ion is $\mathrm{OH}^{-}$, one of the possible hydrogen bonded interactions is of $\mathrm{O}-\mathrm{H}---\mathrm{OH}^{-}$type. In 
this situation, one might expect that the ultimate structure of a given $\left(\mathrm{H}_{2} \mathrm{O}\right)_{n} \mathrm{OH}^{-}$cluster will be dictated by the creation of as many $\mathrm{O}-\mathrm{H}---\mathrm{OH}^{-}$interactions as possible. In such cluster systems, there might arise a situation when after arranging a certain number of $\mathrm{O}-\mathrm{H}$ bonds of $\mathrm{H}_{2} \mathrm{O}$ towards hydroxide $\left(\mathrm{OH}^{-}\right)$, a saturation point is reached and any excess $\mathrm{H}_{2} \mathrm{O}$ molecule added to the cluster system will form hydrogen bonded network to other water molecules, the interaction being of $\mathrm{O}-\mathrm{H}---\mathrm{O}$ type. These hydrogen bonds also leave their mark on the infrared (IR) spectroscopy of these systems. The general trend is the occurrence of intensified red-shifted peaks compared to the position of the $\mathrm{O}$ $-\mathrm{H}$ stretch in free water. Cages formed by $\mathrm{O}-\mathrm{H}---\mathrm{O}$ interaction show their signature on the infrared (IR) spectroscopy of these systems also. This study propose and use a combined SA+DFT strategy to find out high quality structures as well as IR spectroscopic modes. We believe that an initial search on an empirical PES by SA followed by a DFT calculation using the optimized SA structure can lead to the achievement of good quality structures with comparatively reduced computational labour. As a check on the quality of the structure evaluated, spectroscopic modes are determined and the results compared with those available in literature.

\section{Experimental}

\subsection{Potential for the system}

To model the $\left(\mathrm{H}_{2} \mathrm{O}\right)_{n} \mathrm{OH}^{-}$cluster system, we have used intermolecular potential function known as TIP3P as suggested by Jorgensen et al. ${ }^{19-21}$ It is a combination of Lennard Jones and electrostatic or coulomb terms which acts between all intermolecular pairs of charges. The model consists of a rigid water monomer which has three interaction sites. Here, the LJ potentials are present between oxygen atoms. Besides this, the model has charge separation for which it possesses a negative charge $(-0.834 e)$ on oxygen and positive charge $(0.417 e)$ on hydrogen and to accommodate excess negative charge, the charge on oxygen of $\mathrm{OH}^{-}$ ion is $-1.417 e$. Total potential energy expression for the cluster system can be written as

$$
U_{\text {total }}=U_{\mathrm{LJ}}+U_{\text {coul }}
$$

where $U_{\mathrm{LJ}}$ is the Lennard Jones interaction energy and $U_{\text {coul }}$ is the coulombic interaction energy. Detailed expressions of the potential energy are given in the paper by Jorgensen et al. ${ }^{19-21}$ The parameters for the potential function are given in table 1 . It must be
Table 1. Potential energy parameters used in model potential.

Parameters for potential energy function

\begin{tabular}{ll}
\hline $\mathrm{r}(\mathrm{OH}), \AA$ & 0.9572 \\
$\angle \mathrm{HOH}, \mathrm{deg}$ & 104.52 \\
$\mathrm{~A} \times 10^{-3}, \mathrm{kcal} \AA^{12} / \mathrm{mol}$ & 582.0 \\
$\mathrm{C}, \mathrm{kcal} \AA^{6} / \mathrm{mol}$ & 595.0 \\
$\mathrm{q}(\mathrm{O})$ & -0.834 \\
$\mathrm{q}(\mathrm{H})$ & 0.417 \\
\hline
\end{tabular}

mentioned, here that other models for water clusters exist, which incorporate more interactions over TIP3P such as SPCE/POL or TIP4P. We perform our initial evaluation of structures using SA with the TIP3P potential because our strategy ultimately is to perform a DFT calculation with the pre-optimized SA structures. Since the TIP3P-supported structures will be further verified at the DFT level, we desist from using other models such as the SPCE/POL or TIP4P.

\subsection{Simulated annealing method}

After generating potential energy for the system, we use stochastic global optimizer called simulated annealing to determine the critical points which are supported by the potential energy function and ultimately determine structures of the water-hydride clusters. SA is a technique which borrows its working principle from the physical process of annealing. In physical annealing, a moistened melt of metal is heated to a very high temperature and then cooled down very slowly to reach the thermodynamic minimum energy state. The origin of the working of SA is based on metropolis sampling scheme. If find out the minima (global and local) of a potential energy function, one has to start with a randomly generated and guessed solution. This solution is far away from the actual solution. Here, one needs to modify the starting solution using some criteria so that at the end, the desired minimum (global and local) solution is found out. The solution with which the process is started can be updated in the following way, for the initial set, one coordinate is randomly selected say $y_{k}^{0}$. Then, a random change is given in the following way,

$$
y_{k}^{1}=y_{k}^{0}+(-1)^{i} \Delta R \text {. }
$$

In eq. (2), $i$ is a random integer, $R$ is a random number (between 0 and 1) and $\Delta$ is the desired amplitude of change. Now, the variable can change in both the positive and negative direction. After obtaining the new set of coordinates, one can calculate $U_{\text {total }}^{1}$ where $U_{\text {total }}^{1}$ is the total potential energy from the new set. 
The $U_{\text {total }}^{1}$ is evaluated by using the updated coordinates and eq. (1) to calculate the energy of the instantaneous structures at the TIP3P level of theory. The value of $U_{\text {total }}^{1}$ can be compared with the potential energy $U_{\text {total }}^{0}$, which is evaluated with the older set of coordinates. The move is accepted when $U_{\text {total }}^{1}<U_{\text {total }}^{0}$ and if the reverse occurrs, the move is not rejected directly and it is subjected to the Metropolis Sampling Test. Now we have constructed a function, generally known as objective function $(F)$

$$
F=\left(U_{\text {total }}-U_{\mathrm{L}}\right)^{2},
$$

where $U_{\mathrm{L}}$ is lower bound energy and its value is supplied. Through the search, the value of $F$ will be minimized and it is obtained when $U_{\text {total }}$ is minimized. With $U_{\text {total }}^{0}, F^{0}$ is evaluated and with $U_{\text {total }}^{1}, F_{1}$ is evaluated. Now, if $\Delta F\left(F_{1}-F_{0}\right)$ is negative, the move is accepted, otherwise it is subjected to the Metropolis Sampling Test.

In SA, there is a temperature-like quantity $\left(T_{\mathrm{at}}\right)$, which is similar to annealing temperature at every step. It helps to evaluate the sampling probability, which is

$$
P_{\mathrm{S}}=\exp \left(\frac{-\Delta F}{T_{\mathrm{at}}}\right)
$$

The value of $P_{\mathrm{S}}$ is in between 0 and 1 . A random number $R$ which is also in between 0 and 1 is called and it is compared with $P_{\mathrm{S}}$. If $P_{\mathrm{S}}$ is larger than $R$, the move is accepted, otherwise it is rejected. In the initial stage $T_{\text {at }}$ is kept high so that the value of $P_{\mathrm{S}}$ will be about one and hence most moves will pass the Metropolis Sampling Test. Initially, as the $T_{\text {at }}$ is high, the system can overcome any potential energy barrier and the correct direction is achieved easily. The temperature is decreased gradually which is called the annealing schedule. The $T_{\text {at }}$ is a parameter which controls the thermal fluctuation. At higher $T_{\text {at }}$, thermal fluctuation is also high and it helps the system to move out from a local attractive basin towards a deeper energy basin. In later stage of the search, the annealing temperature as well as thermal fluctuation decreases so that the value of $P_{\mathrm{S}}$ becomes low. It is essential as in the later stage only, those moves are accepted for which energy decreases. Gradually, when $T_{\text {at }} \rightarrow 0$, the system finds out the desired solution.

\subsection{Quantum chemical calculations}

The SA-based search has generated various low-lying energy structures for $\left(\mathrm{H}_{2} \mathrm{O}\right)_{n} \mathrm{OH}^{-}$system $(n=1-6)$. Now, the geometries of the structures are used as an input for DFT calculations ([with basis set 6-311G++ (d, p) and B3LYP functional]) to obtain frequencies of the IR modes. We have used Gaussian package for quantum chemical calculations. Energies of SA and DFT calculation are different. This is because SA evaluates the energy from empirical potential energy function while DFT evaluates the total energy of the system concerned.

\section{Results and discussion}

\subsection{Structures and spectroscopy of $\left(\mathrm{H}_{2} \mathrm{O}\right)_{n} \mathrm{OH}^{-}$ clusters obtained from SA-based search and DFT calculations}

In the literature, vibrational frequencies of waterhydroxide clusters are reported. ${ }^{50,51,56,93}$ The IR spectrum of the global minimum clusters are shown in figures 1 and 2. While figure 1 shows IR peaks in the entire frequency range, figure 2 depicts peaks in the range of $3400-4000 \mathrm{~cm}^{-1}$. This is the frequency range where the effects of hydrogen bonding on the stretching modes are expected to be visible. This is done to highlight the high frequency modes and in the larger clusters to prominently display the red-shifted hydrogen bonded peaks with respect to the free $\mathrm{O}-\mathrm{H}$ stretches. The spectral details are depicted in table 2 .

(i) $\left(\mathrm{H}_{2} \mathrm{O}\right) \mathrm{OH}^{-}$

The SA and DFT based structures show close similarity. Both of the structures show one hydrogen atom close to the coordinating $\mathrm{OH}^{-}$ion. The structures are shown in figure $3 \mathrm{a}$ and $\mathrm{b}$, respectively. The $\mathrm{H}$-bond lengths are different in figure $3 a$ and $b$. This is because the first one is obtained after SA calculation and the second after DFT. The SA calculation uses only a empirical potential and the results are expected to be quantitatively different from the DFT one. The empirical potential in general underestimates the strength of the interaction and hence predicts a larger length as opposed to the more accurate DFT evaluation.

The spectrum of this cluster is shown in figures 1 and 2. In this system, only two peaks of weak intensities are obtained. These are $3816.11 \mathrm{~cm}^{-1}$ and $3849.80 \mathrm{~cm}^{-1}$ with intensities 18.4159 and 0.8765 , respectively. The main contribution to the peak at $3816.11 \mathrm{~cm}^{-1}$ occurs due to vibration of the $O(4)$ and $H(5)$ bonds, while the vibration of the $O(1)-H(3)$ bond contributes to the peak at $3849.80 \mathrm{~cm}^{-1}$.

\section{(ii) $\left(\mathrm{H}_{2} \mathrm{O}\right)_{2} \mathrm{OH}^{-}$}

Structures obtained using the SA and DFT are very similar. In both of the cases, there are two $\mathrm{O}-\mathrm{H} \cdots \mathrm{O}$ 


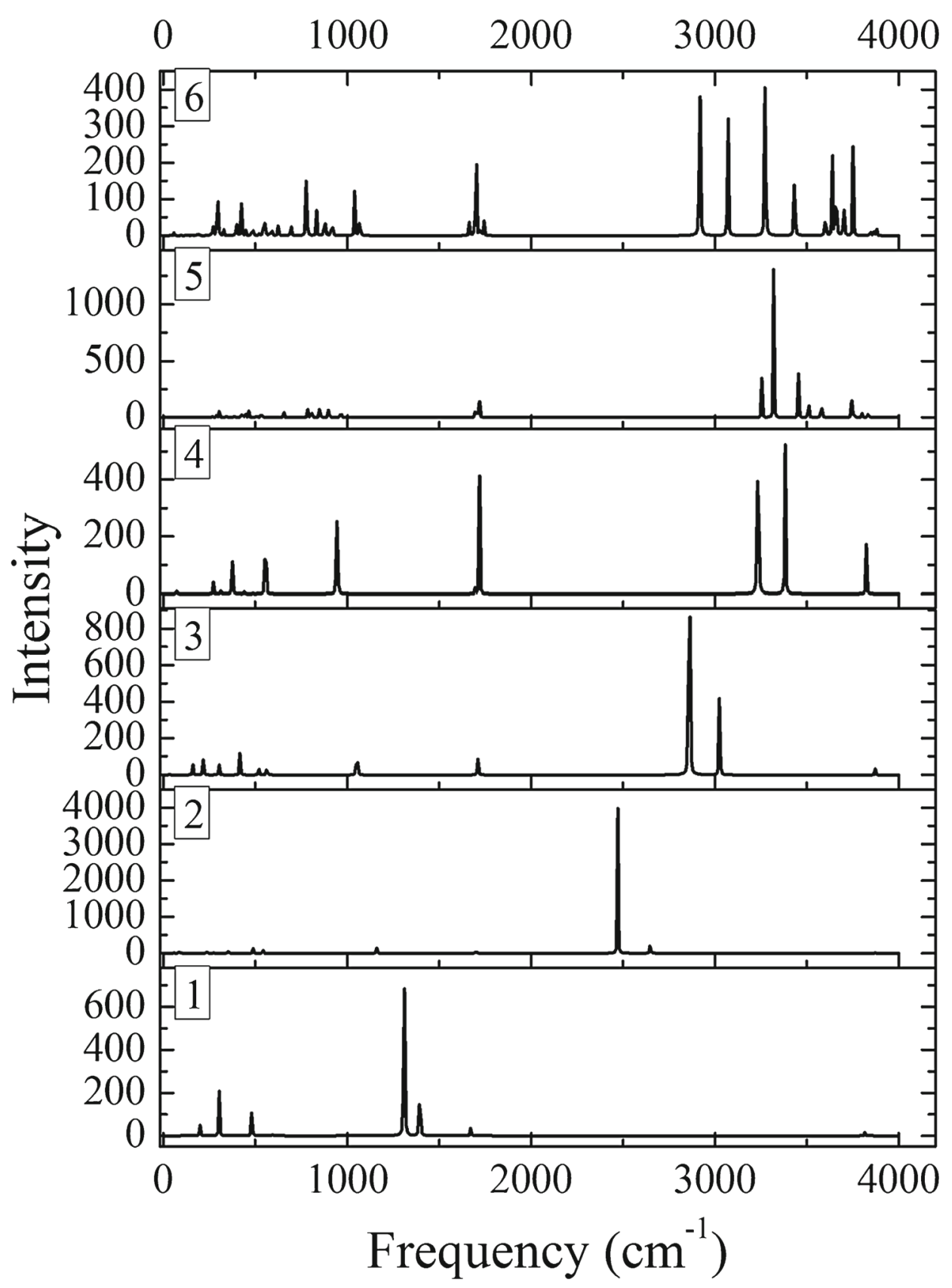

Figure 1. IR spectrum of $\left(\mathrm{H}_{2} \mathrm{O}\right)_{n} \mathrm{OH}^{-}$cluster systems.

hydrogen bonds of equal strength and proximity with the central $\mathrm{OH}^{-}$ion. The other two hydrogen atoms are away from each other in order to minimize the Coulombic interaction between them. The structures are shown in figure $4 \mathrm{a}$ and $\mathrm{b}$, respectively. The local structure from $\mathrm{SA}$ is shown in figure $4 \mathrm{c}$ and it shows that the two $\mathrm{O}-\mathrm{H} \cdots \mathrm{O}$ interactions are of almost equal strength and equal proximity. It is seen from the structures that the two H-bonds present in each have certain noticeable differences. Specifically in figure $4 \mathrm{c}$ the two $\mathrm{H}-$ bonds are unequal. This is because, figure $4 \mathrm{c}$ is a local structure and has some degree of asymmetry compared to the global which is totally symmetric. Generally, in this type of cluster systems the relatively symmetric structure seems to be lower in energy.

The peak at $3842.70 \mathrm{~cm}^{-1}$ with relative intensities of 3.5178 occurs due to the vibration of $O(7)-H(8)$ mode. There are two peaks at $3870.03 \mathrm{~cm}^{-1}$ and $3870.21 \mathrm{~cm}^{-1}$ and their intensities are 3.9091 and 4.3991 , respectively. Both of the peaks occur due to $O(1)-H(2)$ bond vibration coupled with $O(4)-H(5)$ bond vibration. 


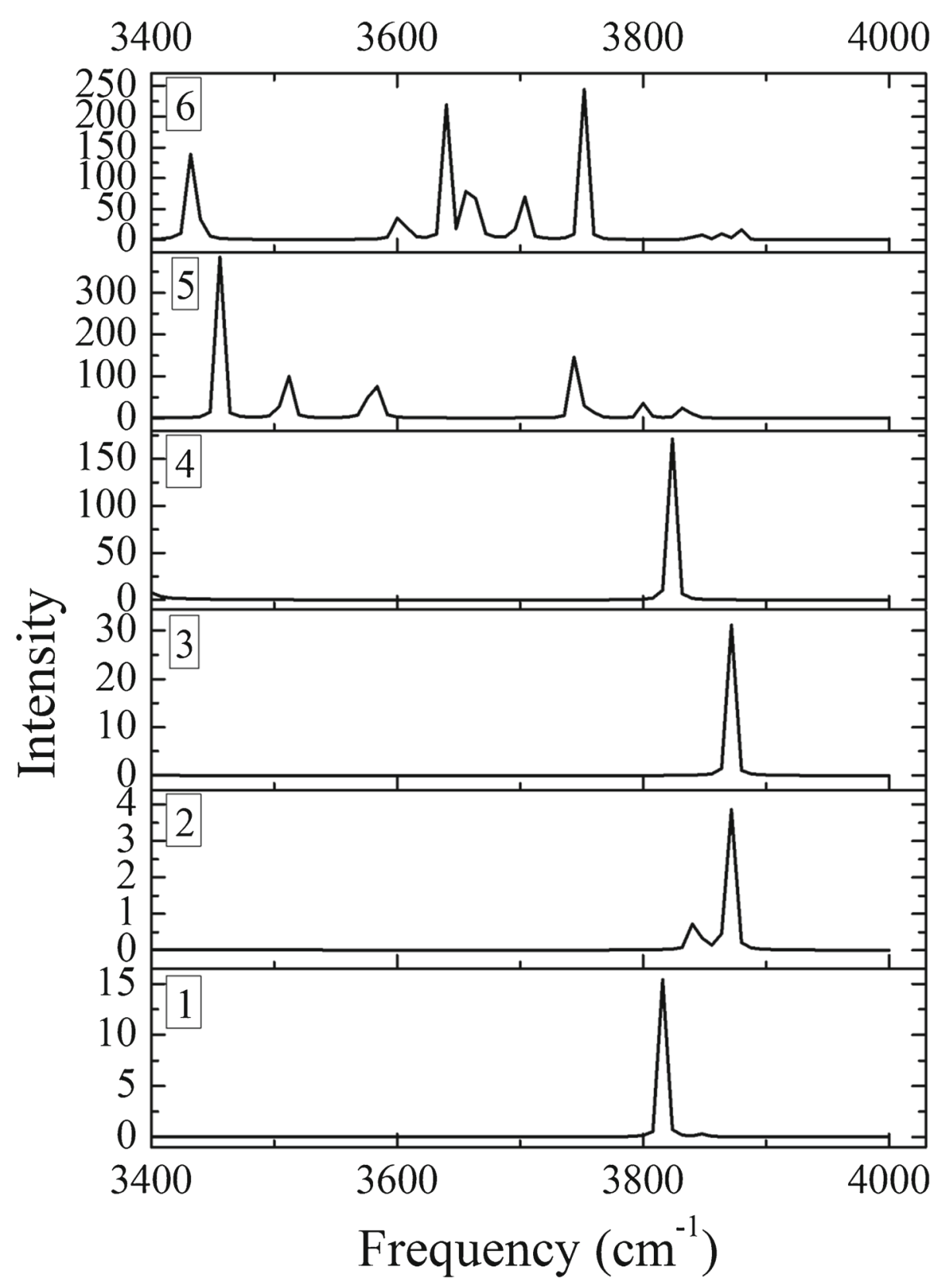

Figure 2. IR spectrum from 3400 to $4000 \mathrm{~cm}^{-1}$ of $\left(\mathrm{H}_{2} \mathrm{O}\right)_{n} \mathrm{OH}^{-}$cluster systems.

(iii) $\left(\mathrm{H}_{2} \mathrm{O}\right)_{3} \mathrm{OH}^{-}$

Structures with SA and DFT based method are shown in figure $5 \mathrm{a}$ and $\mathrm{b}$, respectively. The SA-based structure similar to a triangular structure while the DFTbased structure looks similar to a tetrahedral one. In both of the cases, there are three $\mathrm{O}-\mathrm{H} \cdots \mathrm{O}$ hydrogen bond interactions of equal strength and equal length. The higher energy structure (local) obtained from SA is shown in figure 5c. The structure is similar to the lower energy structure obtained from SA with slight difference in the three $\mathrm{O}-\mathrm{H} \cdots \mathrm{O}$ interaction lengths.
The IR spectrum of the cluster is shown in figures 1 and 2. For this system we have five vibration frequencies which give rise to five peaks out of which the peak at $3023.40 \mathrm{~cm}^{-1}$ has high intensity of 754.9940 and it occur due to $O(1)-H(2), O(4)-H(5)$ and $O(7)-H(8)$ vibration. The peak at $3851.99 \mathrm{~cm}^{-1}$ with intensity 0.0025 and originates from $O(10)-H(11)$ vibrational mode. The peak at $3870.89 \mathrm{~cm}^{-1}$ with intensity of 11.2489 occur due to $O(1)-H(3)$ and $O(7)-H(9)$ vibrational modes. The peaks at $3871.04 \mathrm{~cm}^{-1}$ with 11.5559 intensity and at $3871.51 \mathrm{~cm}^{-1}$ with intensity of 13.4634 occur due to bond vibrations involving $O(1)-H(3), O(4)-H(6)$ and $O(7)-H(9)$ simultaneously. 
Table 2. Infrared spectroscopic modes of $\left(\mathrm{H}_{2} \mathrm{O}\right)_{n} \mathrm{OH}^{-}$clusters.

Spectral data of $\left(\mathrm{H}_{2} \mathrm{O}\right)_{n} \mathrm{OH}^{-}$clusters $(\mathrm{O}-\mathrm{H})$ stretching frequencies $\left(\mathrm{cm}^{-\mathbf{1}}\right)$

\begin{tabular}{llll}
\hline Species & DFT calculated (harmonic) & DFT calculated (anharmonic) & Experimental $^{4-12}$ \\
\hline$\left(\mathrm{H}_{2} \mathrm{O}\right) \mathrm{OH}^{-}$ & $1669,2144,3816,3849$ & $1491,2029,3656,3866,3877$ & $055,3380,3653$ \\
$\left(\mathrm{H}_{2} \mathrm{O}\right)_{2} \mathrm{OH}^{-}$ & $2647,3842,3870$ & $2745,3553,3858,3882$ & $2700,3660,3694$ \\
$\left(\mathrm{H}_{2} \mathrm{O}\right)_{3} \mathrm{OH}^{-}$ & $2859,3023,3851,3870,3871$ & $2609,2631,2674,3682,3872,3874$ & 2600,3695 \\
$\left(\mathrm{H}_{2} \mathrm{O}\right)_{4} \mathrm{OH}^{-}$ & $3218,3233,3381,3820$, & $2843,2875,2964,2968,3434,3497$, & $2900,3447,3489,3615,3675$ \\
& $3823,3826,3856$ & $3502,3571,3620,3633,3654,3683$ & \\
$\left(\mathrm{H}_{2} \mathrm{O}\right)_{5} \mathrm{OH}^{-}$ & $3253,3318,3454,3508$, & $3096,3298,3357,3456,3491,3523$, & $3446,3532,3572,3621$, \\
& $3579,3744,3754,3801$, & $3541,3569,3605,3629,3654$, & 3648,3700 \\
& $3830,3835,3848$ & 3698,3853 & \\
$\left(\mathrm{H}_{2} \mathrm{O}\right)_{6} \mathrm{OH}^{-}$ & $3068,3272,3433,3602,3639$, & $2975,3167,3400,3420,3430$, & \\
& $3659,3700,3751,3844,3866$, & $3472,3546,3642,3869$, & \\
& 3867,3878 & 3875,3876 & \\
\hline
\end{tabular}

\section{(iv) $\left(\mathrm{H}_{2} \mathrm{O}\right)_{4} \mathrm{OH}^{-}$}

For this cluster system, the structure with SA and DFT based methods are shown in figure $6 \mathrm{a}$ and $\mathrm{b}$, respectively. Both the structures are present on the same line with minor difference in angular disposition and the DFT-based structure is more symmetric than the other one. In both the structures $\mathrm{O}-\mathrm{H} \cdots \mathrm{O}$ bond interaction with the central $\mathrm{OH}^{-}$ion is present. The local minimum structure with less symmetric and lesser number of $\mathrm{O}-\mathrm{H} \cdots \mathrm{O}$ bonds with central $\mathrm{OH}^{-}$ion is shown in figure $6 \mathrm{c}$.

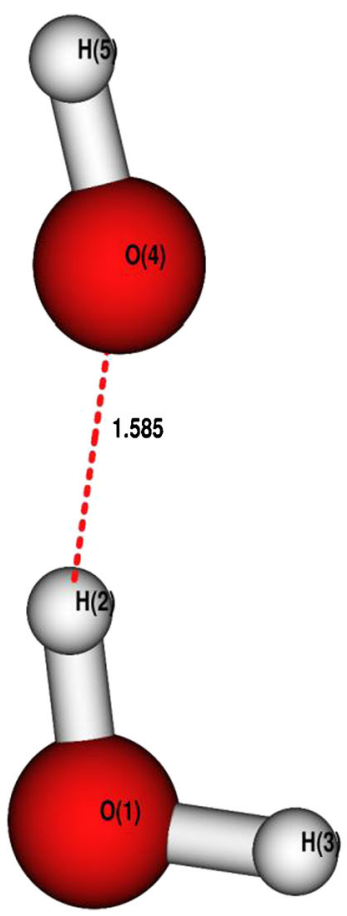

(a)

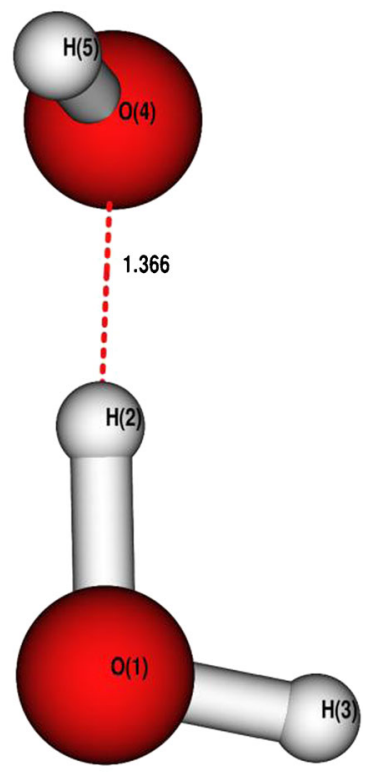

(b)
Figure 3. (a) Global structure $(\mathrm{SA})$ of $\left(\mathrm{H}_{2} \mathrm{O}\right) \mathrm{OH}^{-}$. (b) Global structure (DFT) of $\left(\mathrm{H}_{2} \mathrm{O}\right) \mathrm{OH}^{-}$.
In this system, there are eight peaks in the spectrum range of $3000-4000 \mathrm{~cm}^{-1}$. Two peaks with intensities 1165.5844 and 1165.6159 are at the same position of $3233.79 \mathrm{~cm}^{-1}$. Both of them are highly intense

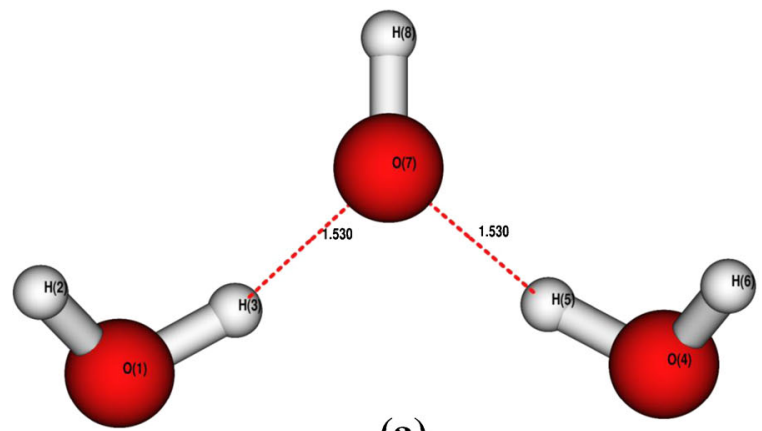

(a)

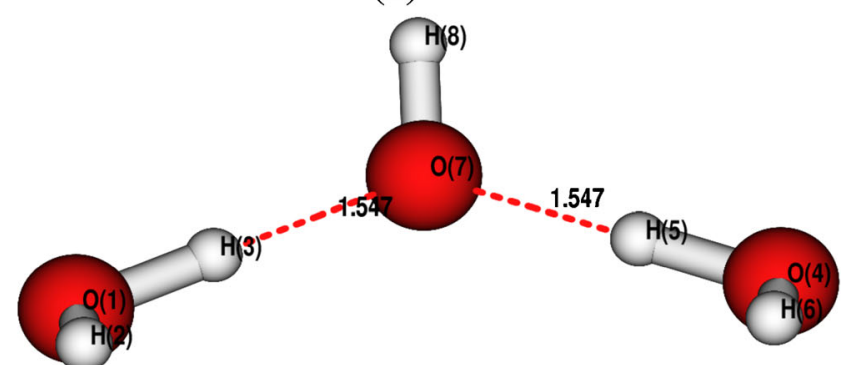

(b)

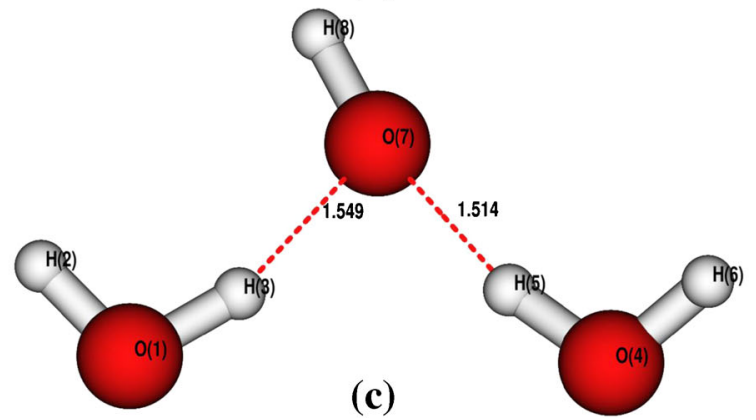

Figure 4. (a) Global structure $(\mathrm{SA})$ of $\left(\mathrm{H}_{2} \mathrm{O}\right)_{2} \mathrm{OH}^{-}$. (b) Global structure (DFT) of $\left(\mathrm{H}_{2} \mathrm{O}\right)_{2} \mathrm{OH}^{-}$. (c) Local structure (SA) of $\left(\mathrm{H}_{2} \mathrm{O}\right)_{2} \mathrm{OH}^{-}$. 


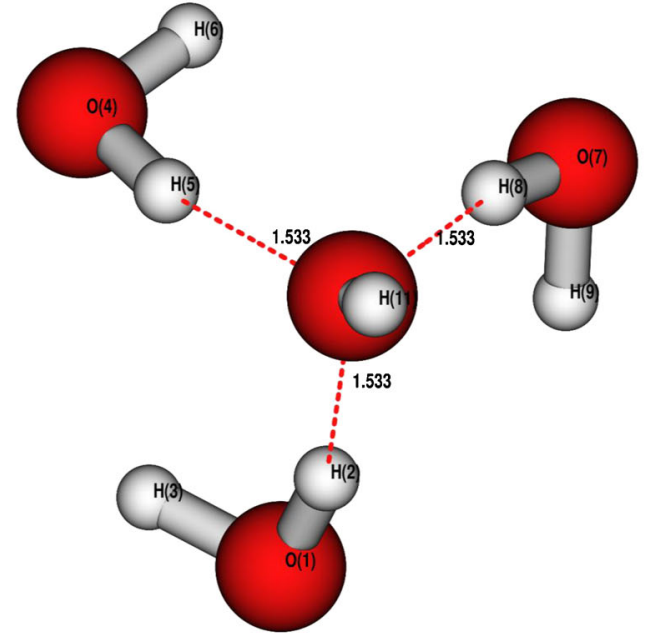

(a)

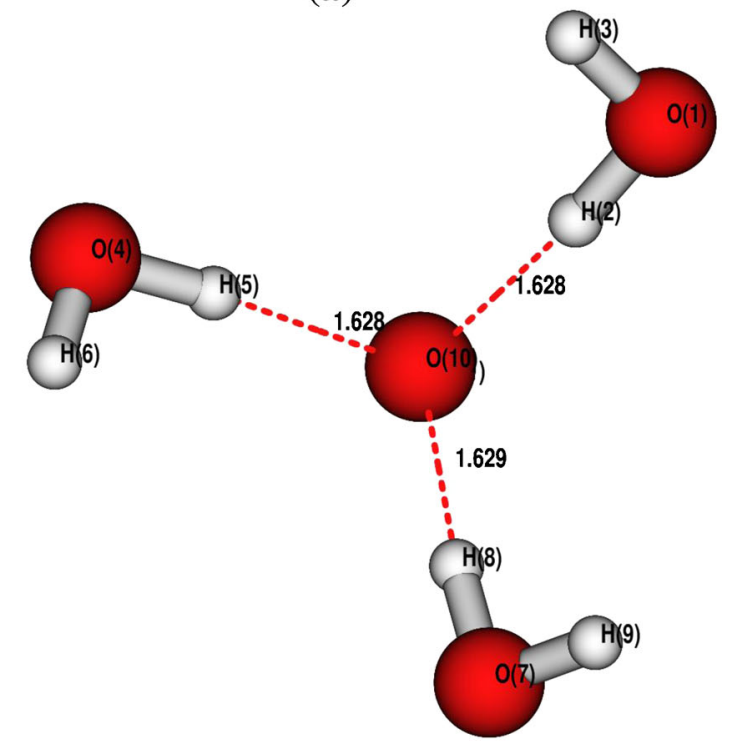

(b)

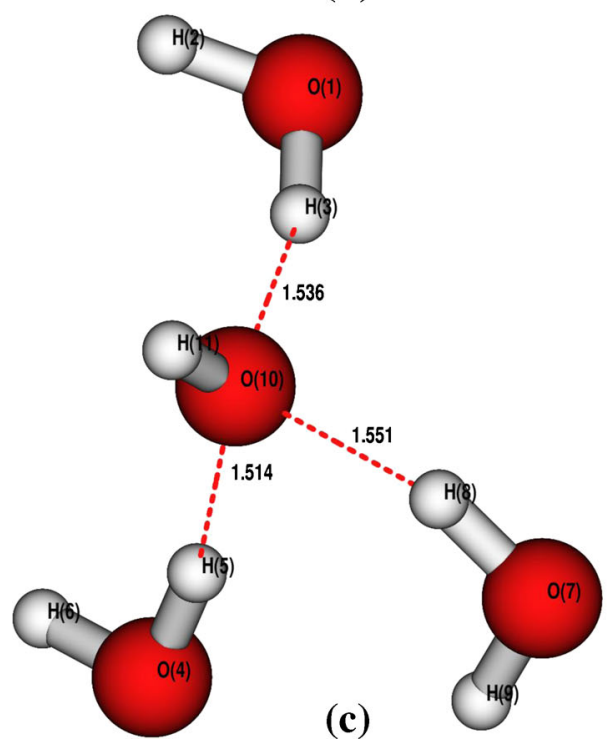

Figure 5. (a) Global structure $(\mathrm{SA})$ of $\left(\mathrm{H}_{2} \mathrm{O}\right)_{3} \mathrm{OH}^{-}$. (b) Global structure (DFT) of $\left(\mathrm{H}_{2} \mathrm{O}\right)_{3} \mathrm{OH}^{-}$. (c) Local structure (SA) of $\left(\mathrm{H}_{2} \mathrm{O}\right)_{3} \mathrm{OH}^{-}$.

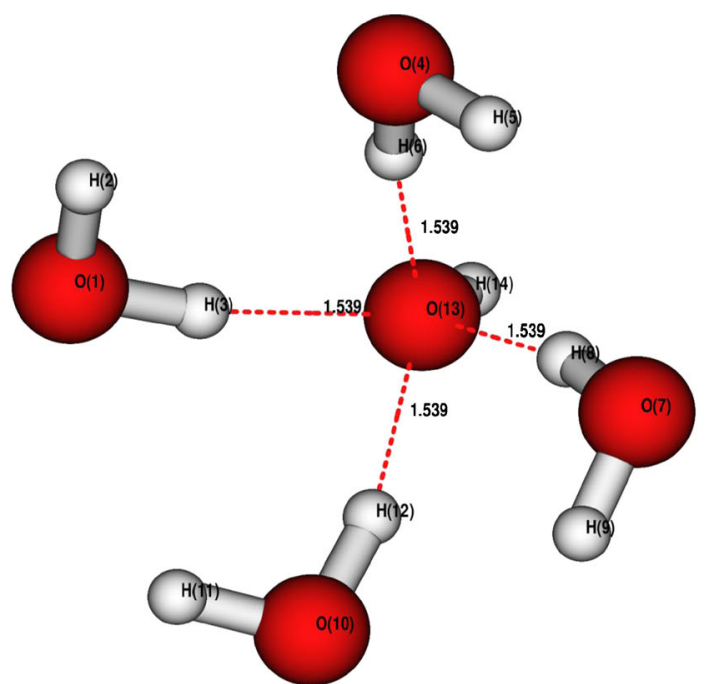

(a)

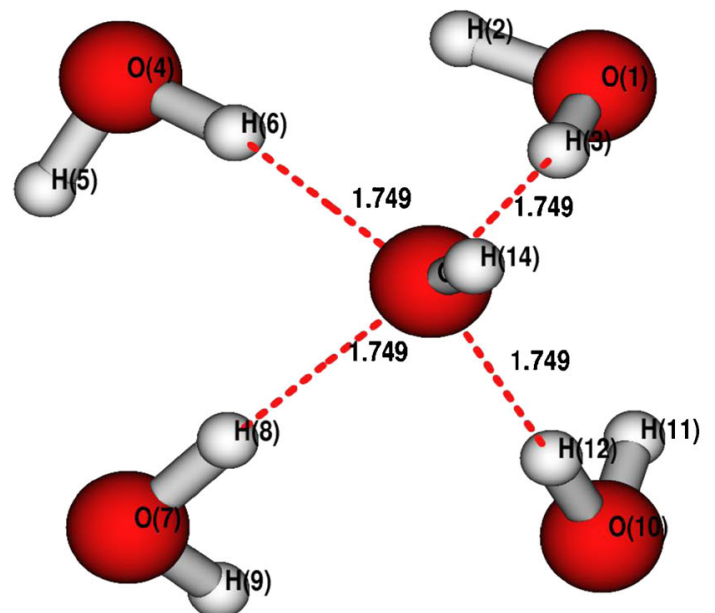

(b)

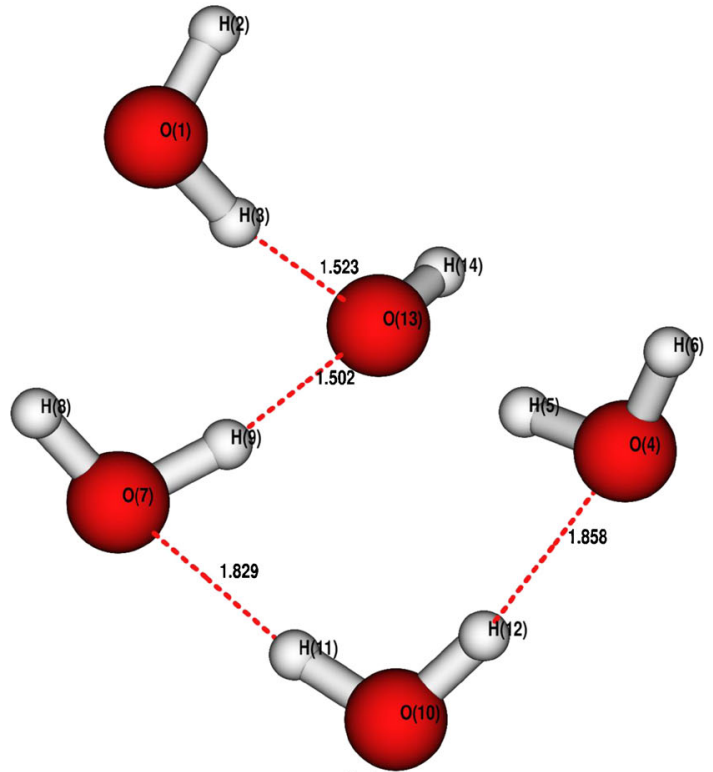

(c)

Figure 6. (a) Global structure $(\mathrm{SA})$ of $\left(\mathrm{H}_{2} \mathrm{O}\right)_{4} \mathrm{OH}^{-}$. (b) Global structure (DFT) of $\left(\mathrm{H}_{2} \mathrm{O}\right)_{4} \mathrm{OH}^{-}$. (c) Local structure (SA) of $\left(\mathrm{H}_{2} \mathrm{O}\right)_{4} \mathrm{OH}^{-}$. 
in the spectrum and arise due to strong contribution of $O(7)-H(8)$ and $O(1)-H(3)$ vibrational modes with weak contribution of $O(4)-H(6)$ and $O(10)-$ $H(12)$ vibrational modes. The peak at $3381.26 \mathrm{~cm}^{-1}$ with strong intensity of 1048.8439 also originates from the above bond vibrations. The peaks at $3820.74 \mathrm{~cm}^{-1}$ (67.2507 peak intensity), $3823.80 \mathrm{~cm}^{-1}$ (79.3363 peak intensity), $3823.80 \mathrm{~cm}^{-1}$ (79.3374 peak intensity) and $3826.61 \mathrm{~cm}^{-1}$ (0.0002 peak intensity) occur due to vibrations of $O(1)-H(2), O(4)-H(5), O(7)-H(9)$ and $O(10)-H(11)$ bonds. The peak at $3868.69 \mathrm{~cm}^{-1}$ (0.0107 peak intensity) occurs due to $O(13)-H(14)$ vibrational mode. The spectrum of the above system is shown in figures 1 and 2.

\section{(v) $\left(\mathrm{H}_{2} \mathrm{O}\right)_{5} \mathrm{OH}^{-}$}

The SA and DFT based structures for this system are shown in figure $7 \mathrm{a}$ and $\mathrm{b}$, respectively. The structures are broadly similar with all the five water molecules having close $\mathrm{O}-\mathrm{H} \cdots \mathrm{O}$ bond interactions with central $\mathrm{OH}^{-}$ion. However angular dispositions of the non-coordinating hydrogen atoms are slightly different in these two structures. The structure related to local energy is shown in figure $7 \mathrm{c}$. Here, the number of hydrogen-bonded interactions with the central $\mathrm{OH}^{-}$ion is less than that of global structure.

The IR spectrum corresponding to this system is shown in figures 1 and 2. A total number of 11 peaks are observed in the spectrum. The most intense peak is observed at $3318.59 \mathrm{~cm}^{-1}(1306.5764$ peak intensity) which is due to equally strong contribution of $O(1)-H(2)$ and $O(13)-H(14)$ vibrational modes with weak contribution of $O(4)-H(6)$, $O(7)-H(9)$ and $O(10)-H(12)$ vibrational modes. The peak at $3253.79 \mathrm{~cm}^{-1}$ (424.9876 peak intensity) occur mainly due to $O(1)-H(2)$ and $O(13)-H(14)$ vibrations. The peak at $3454.58 \mathrm{~cm}^{-1}$ (403.4347 peak intensity) occur due to $O(4)-H(6)$ and $O(7)-H(9)$, at $3508.46 \mathrm{~cm}^{-1}$ (391.9892 peak intensity) due to $O(4)-H(6), O(7)-H(9)$ and $O(10)-H(12)$ and at $3579.67 \mathrm{~cm}^{-1}$ (486.2181 peak intensity) because of $O(10)-H(12)$ interaction with moderate contribution of $O(4)-H(6)$ and $O(7)-H(9)$ interactions. The other two intense peaks occur at $3744.34 \mathrm{~cm}^{-1}(190.3778$ peak intensity) and at $3754.82 \mathrm{~cm}^{-1}(130.4440$ peak intensity). Both these peaks occur due to $O(7)-H(8)$ and $O(10)-H(11)$ bond interactions.

\section{(vi) $\left(\mathrm{H}_{2} \mathrm{O}\right)_{6} \mathrm{OH}^{-}$}

The two structures obtained from SA and DFT based calculations are shown in figure $8 \mathrm{a}$ and $\mathrm{b}$, respectively. Here, we can again see that both the structures

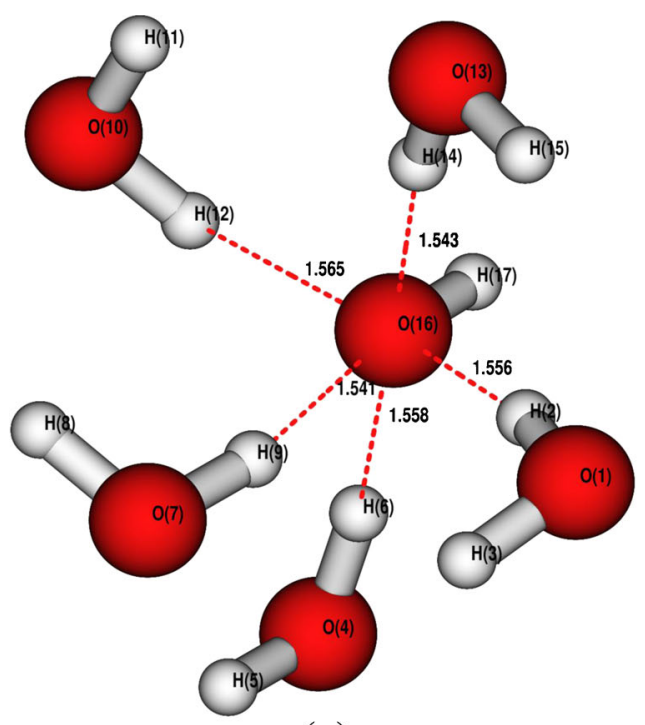

(a)

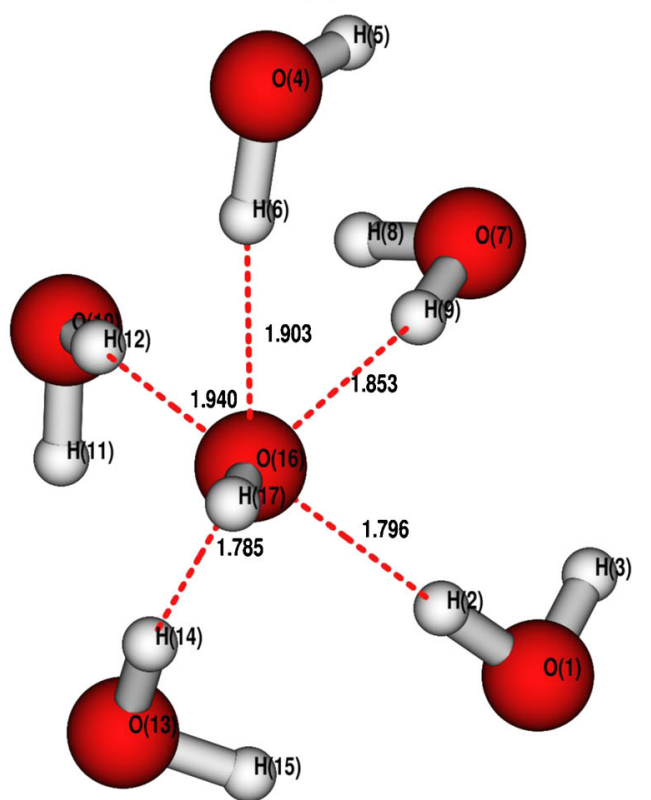

(b)

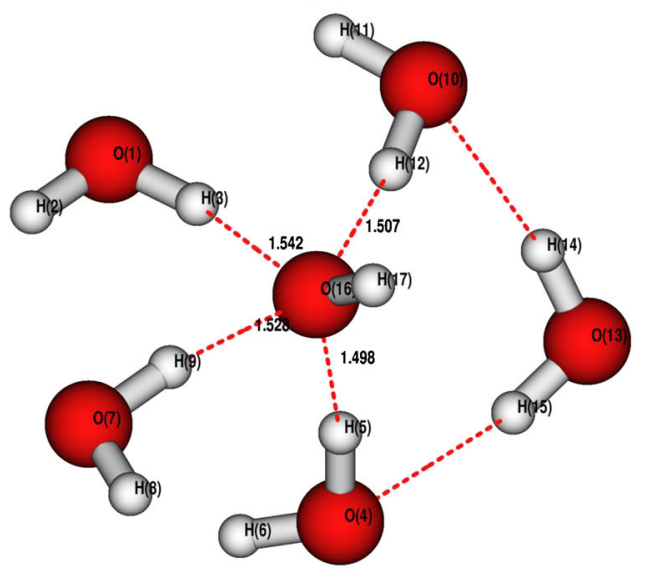

(c)

Figure 7. (a) Global structure (SA) of $\left(\mathrm{H}_{2} \mathrm{O}\right)_{5} \mathrm{OH}^{-}$. (b) Global structure (DFT) of $\left(\mathrm{H}_{2} \mathrm{O}\right)_{5} \mathrm{OH}^{-}$. (c) Local structure (SA) of $\left(\mathrm{H}_{2} \mathrm{O}\right)_{5} \mathrm{OH}^{-}$. 


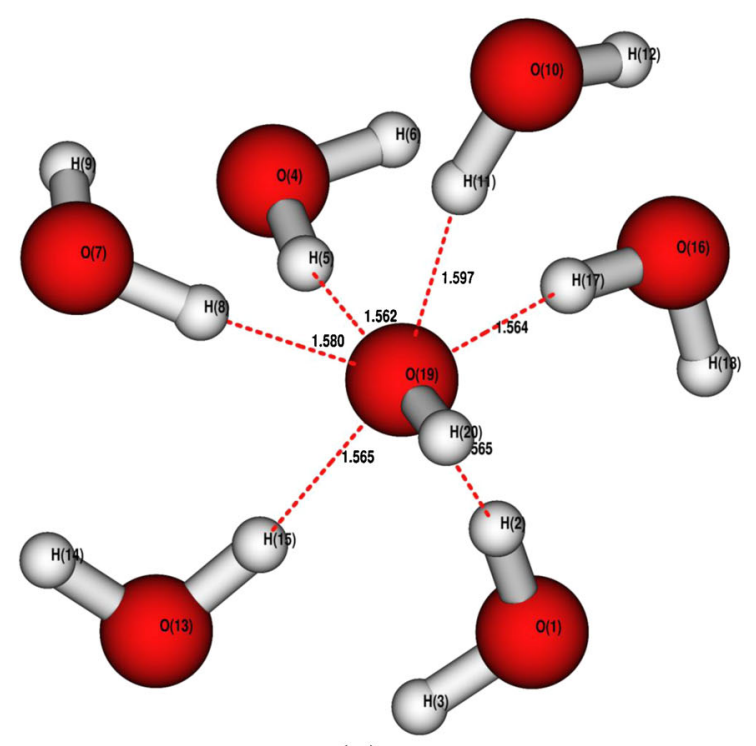

(a)

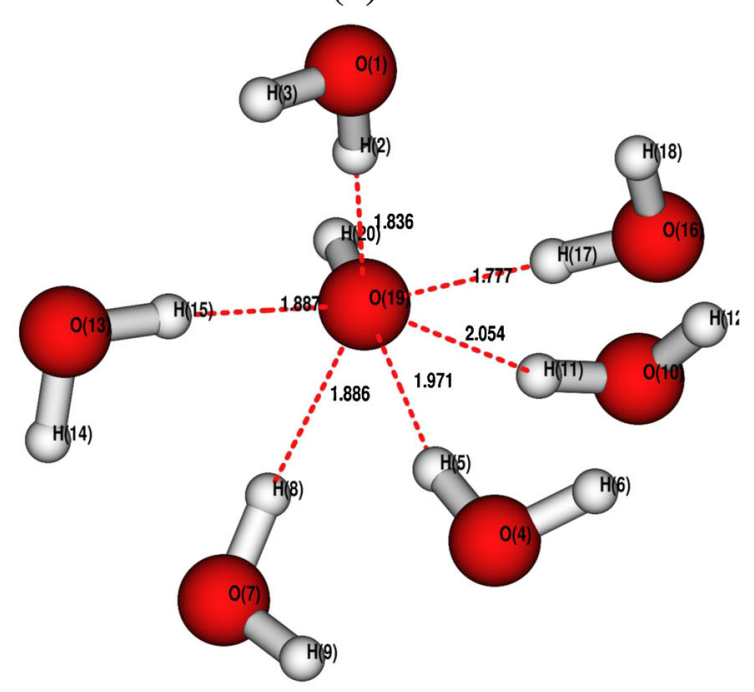

(b)

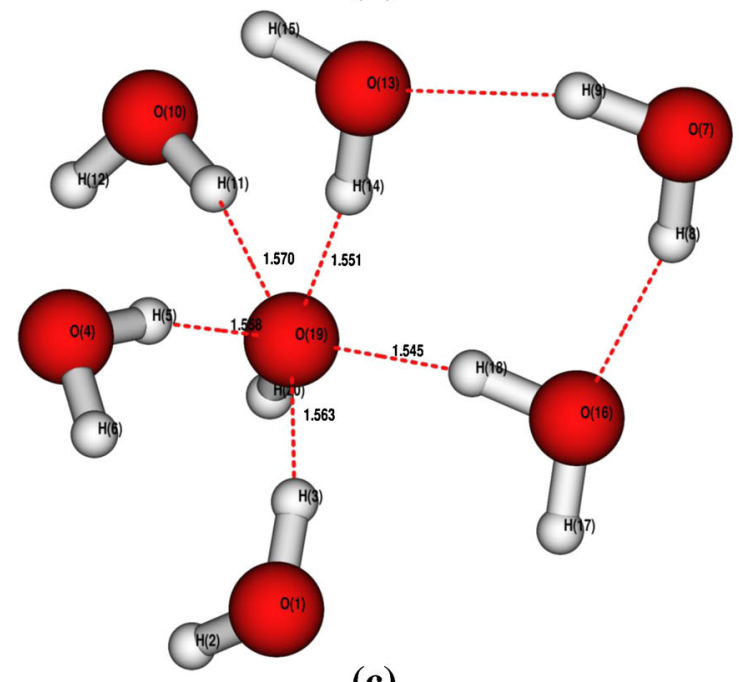

(c)

Figure 8. (a) Global structure (SA) of $\left(\mathrm{H}_{2} \mathrm{O}\right)_{6} \mathrm{OH}^{-}$. (b) Global structure (DFT) of $\left(\mathrm{H}_{2} \mathrm{O}\right)_{6} \mathrm{OH}^{-}$. (c) Local structure (SA) of $\left(\mathrm{H}_{2} \mathrm{O}\right)_{6} \mathrm{OH}^{-}$. are essentially similar with minor difference in spatial orientation. In both the structures, all the six water molecules are close to the coordinating $\mathrm{OH}^{-}$ion and are able to form $\mathrm{O}-\mathrm{H} \cdots \mathrm{O}$ hydrogen bonded interactions. Figure $8 \mathrm{c}$ shows the local energy structure where five water molecules are close proximity to the central $\mathrm{OH}^{-}$ion.

The IR spectrum of the cluster obtained from the DFT calculation is shown in figures 1 and 2 . The system generates 12 peaks between 3000 and $4000 \mathrm{~cm}^{-1}$. The peak at $3272.84 \mathrm{~cm}^{-1}(1352.0379$ peak intensity) is the most intense peak and it originates from $O(1)-H(2)$ vibrational mode with moderate contribution from $O(7)-H(8), O(13)-H(15)$ and $O(16)-H(17)$ modes. The second most intense peak is at $3068.52 \mathrm{~cm}^{-1}$ (690.2588 peak intensity) and is due to $O(1)-H(2)$ and $O(16)-H(17)$ interactions. The third one occurs, at $3659.15 \mathrm{~cm}^{-1}$ (572.3403 peak intensity) and occurs, due to $O(4)-H(5), O(4)-H(6)$ interactions. The vibrational mode $O(10)-H(11)$ and $O(10)-H(12)$ contributes to the peak at $3639.64 \mathrm{~cm}^{-1}(227.5687$ peak intensity) and at $3751.28 \mathrm{~cm}^{-1}(249.0348$ peak intensity). The peak at $3433.27 \mathrm{~cm}^{-1}$ (496.8191 peak intensity) occurs due to $O(7)-H(8)$ vibrational mode; at $3602.55 \mathrm{~cm}^{-1}$ (205.1738 peak intensity) occurs due to $O(4)-H(5)$ and $O(4)-H(6)$ vibrational modes. The peak at $3701.00 \mathrm{~cm}^{-1}$ is also moderately intense (245.6067 peak intensity) and it originates from $O(7)-H(8)$ and $O(7)-H(9)$ vibrational modes coupled with $O(4)-H(5)$ and $O(4)-H(6)$ vibrational modes. Another intense peak is observed at $3751.28 \mathrm{~cm}^{-1}$ (249.0348 peak intensity), which is a contribution of $O(10)-H(11)$ vibrational mode coupled with $O(10)-H(12)$ vibrational mode.

The global minimum of all the cluster systems is that for which all the $\mathrm{OH}$ bonds in $\mathrm{H}_{2} \mathrm{O}$ coordinates are close to the central $\mathrm{OH}^{-}$ion and has been observed in earlier studies. ${ }^{50}$ The local minima from $n=4$ onwards have structures with fewer $\mathrm{H}_{2} \mathrm{O}$ molecules coordinating directly with the central $\mathrm{OH}^{-}$ion and engaging in $\mathrm{H}-$ bonds with other $\mathrm{H}_{2} \mathrm{O}$ molecules at some distance away from the central $\mathrm{OH}^{-}$ion.

The energies of SA and DFT calculation are different. This is because SA evaluates the energy from empirical potential energy function while DFT evaluates the total energy of the system concerned. The energy values are given in table 3 .

It is worthwhile to discuss the trends in the hydrogen bond lengths as well as the strength of the H-bond as one changes the size of $\left(\mathrm{H}_{2} \mathrm{O}\right)_{n} \mathrm{OH}^{-}$clusters. As evident from the structures of the clusters depicted in the figures, the H-bond length gradually increases from around 1.37 A for $n=1$ to a high value of 2.054 for 
Table 3. Energy values obtained from SA and DFT calculations.

Energy values from SA and DFT calculation

\begin{tabular}{lcccc}
\hline Species & Global SA $(\mathrm{kcal} / \mathrm{mol})$ & Global DFT $(\mathrm{kcal} / \mathrm{mol})$ & Local SA $(\mathrm{kcal} / \mathrm{mol})$ & Local DFT $(\mathrm{kcal} / \mathrm{mol})$ \\
\hline$\left(\mathrm{H}_{2} \mathrm{O}\right) \mathrm{OH}^{-}$ & -27.2465 & -152.3328 & & \\
$\left(\mathrm{H}_{2} \mathrm{O}\right)_{2} \mathrm{OH}^{-}$ & -73.7531 & -228.8282 & -71.8180 & -228.8053 \\
$\left(\mathrm{H}_{2} \mathrm{O}\right)_{3} \mathrm{OH}^{-}$ & -113.1241 & -305.3183 & -108.7989 & -305.2954 \\
$\left(\mathrm{H}_{2} \mathrm{O}\right)_{4} \mathrm{OH}^{-}$ & -146.7705 & -381.8021 & -132.3167 & -381.7670 \\
$\left(\mathrm{H}_{2} \mathrm{O}\right)_{5} \mathrm{OH}^{-}$ & -175.4105 & -458.2778 & -165.5462 & -458.2400 \\
$\left(\mathrm{H}_{2} \mathrm{O}\right)_{6} \mathrm{OH}^{-}$ & -195.3597 & -534.7640 & -184.6904 & -534.6995 \\
\hline
\end{tabular}

some of the H-bonds in $n=6$ cluster. This result is seen from following the structures evaluated after the DFT stage. This is an expected trend since the single hydroxide ion engages in a larger number of interactions with more water molecules with increasing size of the cluster. Hence, we expect a single $\mathrm{H}$-bond formed by interacting with the oxygen of the hydroxide ion to be larger in length compare to the case in which there is only a single $\mathrm{H}$-bond formed as is the case for $n=1$ cluster. The structure evaluated after the SA stage also shows an increase in the H-bond length, though its effect is not as pronounced as the DFT calculation. This is again expected because the SA calculation employs only an empirical potential and its quantitative accuracy has to be less than a rigorous quantum chemical calculation done at some level of theory. The DFT calculation can also give us the magnitude of $\mathrm{H}$-bond interaction energy for each of the cluster systems. This is now depicted in table 4. The total H-bonded energy shows a gradual increase, as expected, since the number of H-bonds formed increase with increase in cluster size.

In continuation with the ongoing discussion, it is worthwhile to note certain trends in the bond parameters (H-bond distances) after SA calculation and the DFT level. The SA evaluated structures show a gradual increase in H-bonded distances while in DFT, the increase is appreciable. This is a more acceptable trend because the DFT calculation are expected to be more accurate than the SA, which uses the TIP3P model potential for water. The TIP3P model does not incorporate polarization corrections and assumes the

Table 4. Hydrogen bond energies obtained from DFT calculations on $\left(\mathrm{H}_{2} \mathrm{O}\right)_{n} \mathrm{OH}^{-}$cluster systems.

\begin{tabular}{lc}
\hline Species & Hydrogen bond energy (a.u) \\
\hline$\left(\mathrm{H}_{2} \mathrm{O}\right) \mathrm{OH}^{-}$ & -0.046838 \\
$\left(\mathrm{H}_{2} \mathrm{O}\right)_{2} \mathrm{OH}^{-}$ & -0.083663 \\
$\left(\mathrm{H}_{2} \mathrm{O}\right)_{3} \mathrm{OH}^{-}$ & -0.115287 \\
$\left(\mathrm{H}_{2} \mathrm{O}\right)_{4} \mathrm{OH}^{-}$ & -0.140534 \\
$\left(\mathrm{H}_{2} \mathrm{O}\right)_{5} \mathrm{OH}^{-}$ & -0.157687 \\
$\left(\mathrm{H}_{2} \mathrm{O}\right)_{6} \mathrm{OH}^{-}$ & -0.170226 \\
\hline
\end{tabular}

charges to be localized on the hydrogen and oxygen centres. ${ }^{123}$ So in principle, this is a point charge model and does not allow any room for charge delocalization, which is the feature of any quantum chemical system. This is the main reason for the discrepancy in the values at the two levels of theory. Our motivation for using SA was to quickly generate good quality preoptimized structures which though not perfectly accurate in terms of individual bond parameters, are perfect from the point of view of symmetry. After DFT calculation, we can observe that the symmetry of the structure does not change much but the individual bond parameters are obviously updated. Another noticeable feature is the difference in magnitudes of the H-bonds in the local minima as compared to the global one, at least in the smaller size clusters. This can be explained in the sense that the local structures are relatively asymmetric compared to the global one and are bound to show this trend.

We have also calculated the frequencies of these studied cluster systems incorporating anharmonic corrections. This was done with a view to see if coupling of the standard harmonic modes due to the anharmonic perturbation plays a significant role or not. Generally, it is observed that in such systems where the central encapsulated entity is an ion, couple between modes should become prominent and the frequencies evaluated at this level of theory should be closer to the experimentally reported values. In fact, this is what we observe in most cluster sizes, if we refer to the values presented in table 2. Especially, if we look at clusters $\left(\mathrm{H}_{2} \mathrm{O}\right)_{2} \mathrm{OH}^{-},\left(\mathrm{H}_{2} \mathrm{O}\right)_{3} \mathrm{OH}^{-}$, $\left(\mathrm{H}_{2} \mathrm{O}\right)_{4} \mathrm{OH}^{-}$, the position of highly intense ionic $\mathrm{H}_{-}$ bonded is much better evaluated with anharmonic correction and agreement with experiment is close. Specifically, for $\left(\mathrm{H}_{2} \mathrm{O}\right)_{2} \mathrm{OH}^{-}$, the experimental peak ${ }^{4-12}$ is at $2700 \mathrm{~cm}^{-1}$ while the anharmonic theory predicts a value of $2745 \mathrm{~cm}^{-1}$. Harmonic approximation result shows greater deviation with a calculated value of $2647 \mathrm{~cm}^{-1}$. For $\left(\mathrm{H}_{2} \mathrm{O}\right)_{3} \mathrm{OH}^{-}$and $\left(\mathrm{H}_{2} \mathrm{O}\right)_{4} \mathrm{OH}^{-}$, the agreements are excellent where the theoretical predicted frequencies is within 15 wavenumber of the experimentally reported 
one. For $\left(\mathrm{H}_{2} \mathrm{O}\right)_{5} \mathrm{OH}^{-}$, again, the theoretically reported value is within 10 wavenumber So, we can certainly conclude that coupling of modes induced by anharmonicity plays a significant role in this systems.

The evaluated theoretical frequencies can also be compared with reported theoretical ones. However, the correspondence might not be of a high degree as the values change significantly with change in the level of theory. ${ }^{50}$ Our effort with B3LYP functional and with anharmonicity corrections predicts values which do not differ significantly from the experiment.

The NPA (Natural Population Analysis) charges for the global minimum structures $\left(\mathrm{H}_{2} \mathrm{O}\right)_{n} \mathrm{OH}^{-} n=1-6$ have been determined to see if the charges evaluated can throw some light on trends in the VDE (Vertical Detachment Energy) of the cluster systems. Table 5 lists these parameters. Charges on the oxygen and hydrogen atoms of the hydroxyl group and the charges on the hydrogen atoms bound to the oxygen of the $\mathrm{OH}^{-}$by hydrogen bonding are listed in columns 2-4. The fifth colum lists the VDEs for the various cluster sizes. If we look at the individual NPA charges on the atoms, the difference between them are marginal though there seems to be a slight gradual increase in the positive charge on the hydrogen of the hydroxyl ion as the size of the cluster increases. However, the trend is not so regular for oxygen atom of hydroxyl ion. But, it must also be noted that the difference between magnitude of charges on various atoms as the cluster size increases, is only nominal. So, we can come to a reasonably correct conclusion that the strengths of various hydrogen bonds present in the different cluster systems do no differ much. However, the number of hydrogen bonds present increases rapidly with the increase in cluster size. For this mononegative cluster systems, the predominant portion of the excess negative charge is expected to be located on the oxygen atom of the hydroxyl group. As the size of

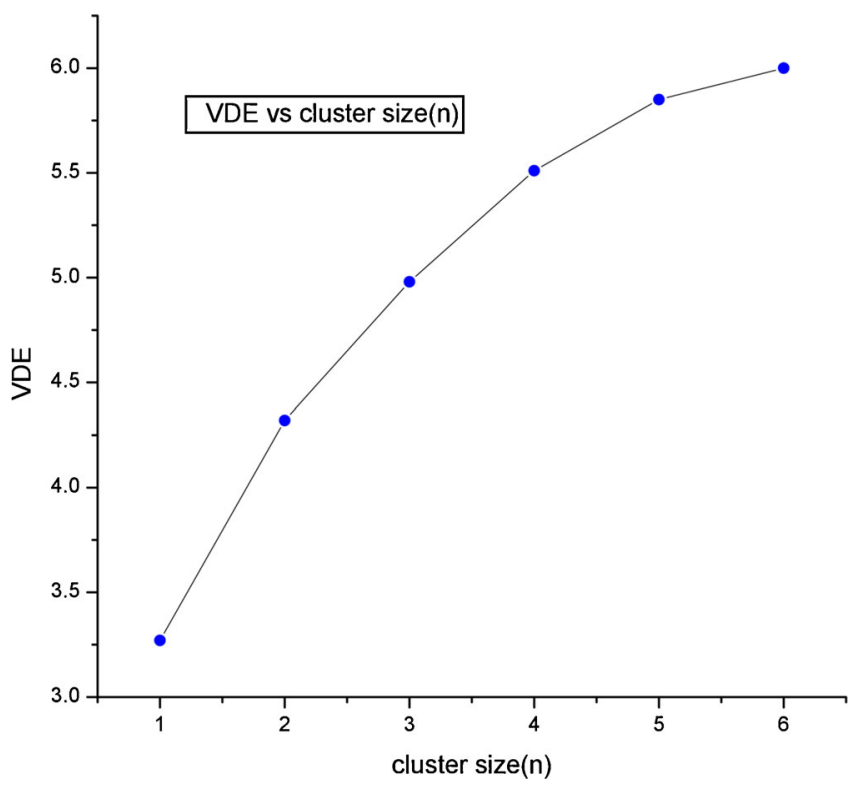

Figure 9. Plot of VDE vs cluster size $(n)$ of $\left(\mathrm{H}_{2} \mathrm{O}\right)_{n} \mathrm{OH}^{-}$ systems.

the cluster increases, the oxygen atom of the hydroxyls gets much strongly bound to the surrounding water molecules on account of the obvious increase in the number of hydrogen-bonded interactions. So, if one calculates the VDE, it is expected that it will be the highest for $\left(\mathrm{H}_{2} \mathrm{O}\right)_{6} \mathrm{OH}^{-}$and least for $\left(\mathrm{H}_{2} \mathrm{O}\right) \mathrm{OH}^{-}$with a gradual increase with increase in size of the clusters. This is reflected in calculation of VDE (table 5) and plot of the variation of VDE with size (figure 9).

\subsection{Atoms in molecule (AIM)-based study of topological analysis}

A study on cluster systems involving H-bonding can be efficiently conducted by using the AIM method of Bader $^{119}$ and the strategy suggested by Koch and

Table 5. NPA charge and VDE calculation of $\left(\mathrm{H}_{2} \mathrm{O}\right)_{n} \mathrm{OH}^{-}$clusters.

\begin{tabular}{lcclc}
\hline \multicolumn{4}{c}{ NPA charge and VDE calculation of $\left(\mathrm{H}_{2} \mathrm{O}\right)_{n} \mathrm{OH}^{-}$clusters } \\
\hline Species & $\begin{array}{c}\text { O atom of } \\
\text { hydroxyl ion }\end{array}$ & $\begin{array}{c}\mathrm{H} \text { atom of } \\
\text { hydroxyl ion }\end{array}$ & $\begin{array}{l}\mathrm{H} \text { atoms of surrounding } \\
\text { water molecules }\end{array}$ & VDE in eV \\
\hline$\left(\mathrm{H}_{2} \mathrm{O}\right) \mathrm{OH}^{-}$ & -1.206 & 0.393 & $\mathrm{H}(2)=0.483$ & 3.27 \\
$\left(\mathrm{H}_{2} \mathrm{O}\right)_{2} \mathrm{OH}^{-}$ & -1.220 & 0.415 & $\mathrm{H}(3)=0.506, \mathrm{H}(5)=0.506$ & 4.32 \\
$\left(\mathrm{H}_{2} \mathrm{O}\right)_{3} \mathrm{OH}^{-}$ & -1.213 & 0.430 & $\mathrm{H}(2)=0.505, \mathrm{H}(5)=0.504, \mathrm{H}(8)=0.505$ & 4.98 \\
$\left(\mathrm{H}_{2} \mathrm{O}\right)_{4} \mathrm{OH}^{-}$ & -1.254 & 0.438 & $\mathrm{H}(3)=0.499, \mathrm{H}(6)=0.500, \mathrm{H}(8)=0.499$, & 5.51 \\
$\left(\mathrm{H}_{2} \mathrm{O}\right)_{5} \mathrm{OH}^{-}$ & -1.278 & 0.443 & $\mathrm{H}(12)=0.500$ & 5.85 \\
& & & $\mathrm{H}(2)=0.496, \mathrm{H}(6)=0.489, \mathrm{H}(9)=0.494$, & 6.00 \\
$\left(\mathrm{H}_{2} \mathrm{O}\right)_{6} \mathrm{OH}^{-}$ & -1.235 & 0.449 & $\mathrm{H}(2)=0.496, \mathrm{H}(14)=0.494$ & \\
& & & $\mathrm{H}(11)=0.484, \mathrm{H}(15)=0.507, \mathrm{H}(17)=0.496$, & \\
\hline
\end{tabular}

Numbers in the bracket correspond to the $\mathrm{H}$ atoms which are attached to the central $\mathrm{OH}^{-}$ion. 
Popelier. ${ }^{120}$ This method has been extensively used in a number of impressive application. ${ }^{121-125}$ To describe an interaction as a hydrogen bonded one, certain criteria should be satisfied based on the AIM technique.

1. The existence of a bond critical point (BCP) between the corresponding hydrogen atom and the acceptor atom engaged in the interaction.

2. Magnitude of the electron density parameter $\rho(r)$ (which is the main criterion to check whether a $\mathrm{H}$-bond has been created or not) evaluated at the BCP must be within a specified range [0.0020.004 a.u]

3. Moreover, the Laplacian of electron density at the BCP $\left(\nabla^{2} \rho_{c}\right)$ must be + ve and should be within the range of $0.02-0.15$ a.u.
4. Bonded radius of the hydrogen atom and the corresponding acceptor atom must individually be less than the corresponding van der Waals radii while in the non-bonded state, further, an estimate of H-bond energy can be made as this is connected to the local potential energy density at the hydrogen bond critical point along with the atomic volume element using the following equation.

$$
E_{\mathrm{Hb}}=-\frac{a_{0}^{3}}{2} V_{\mathrm{ep}} .
$$

We have pictorially depicted the AIM-evaluated structures connecting the electron density $\rho(r)$ along with the location of critical points in figure 10a-f. Moreover, we report in tabular form, the magnitudes of all the necessary parameters evaluated using the AIM study and

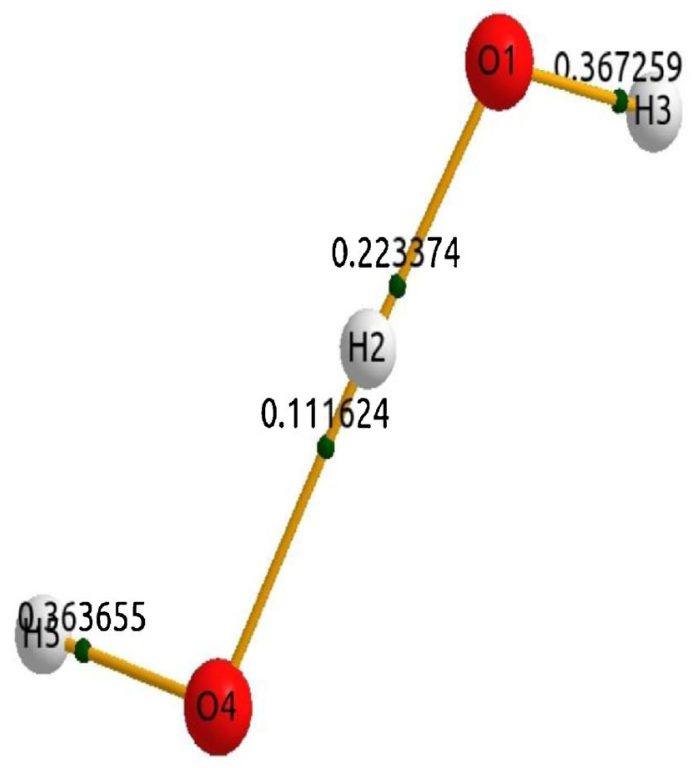

(a)

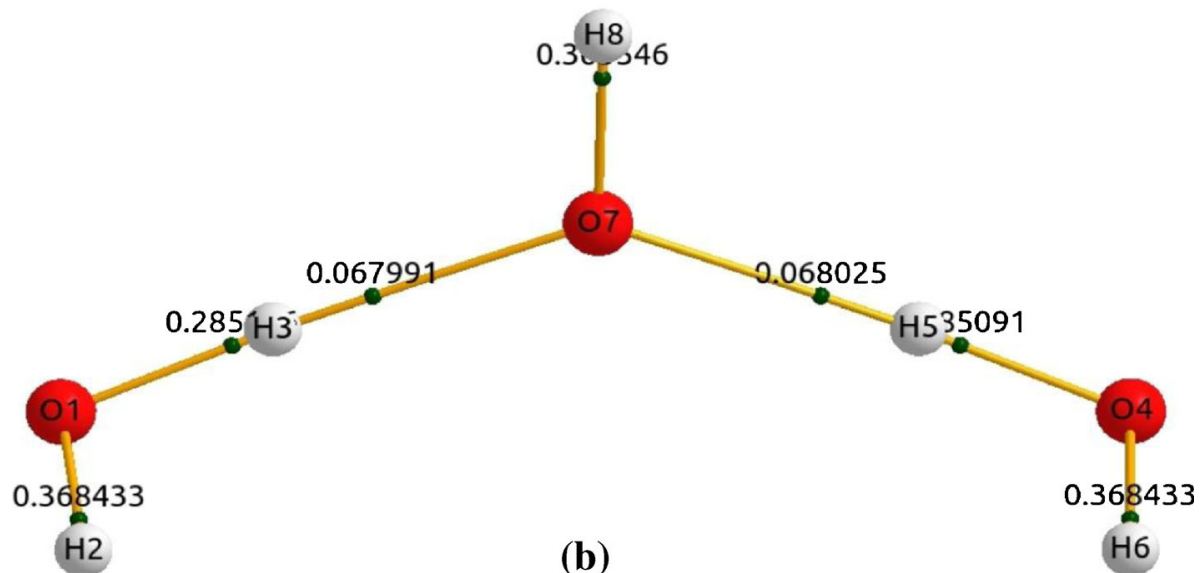

Figure 10. (a) Global structure (AIM) of $\left(\mathrm{H}_{2} \mathrm{O}\right) \mathrm{OH}^{-}$. (b) Global structure (AIM) of $\left(\mathrm{H}_{2} \mathrm{O}\right)_{2} \mathrm{OH}^{-}$. (c) Global structure (AIM) of $\left(\mathrm{H}_{2} \mathrm{O}\right)_{3} \mathrm{OH}^{-}$. (d) Global structure (AIM) of $\left(\mathrm{H}_{2} \mathrm{O}\right)_{4} \mathrm{OH}^{-}$. (e) Global structure (AIM) of $\left(\mathrm{H}_{2} \mathrm{O}\right)_{5} \mathrm{OH}^{-}$. (f) Global structure (AIM) of $\left(\mathrm{H}_{2} \mathrm{O}\right)_{6} \mathrm{OH}^{-}$. 


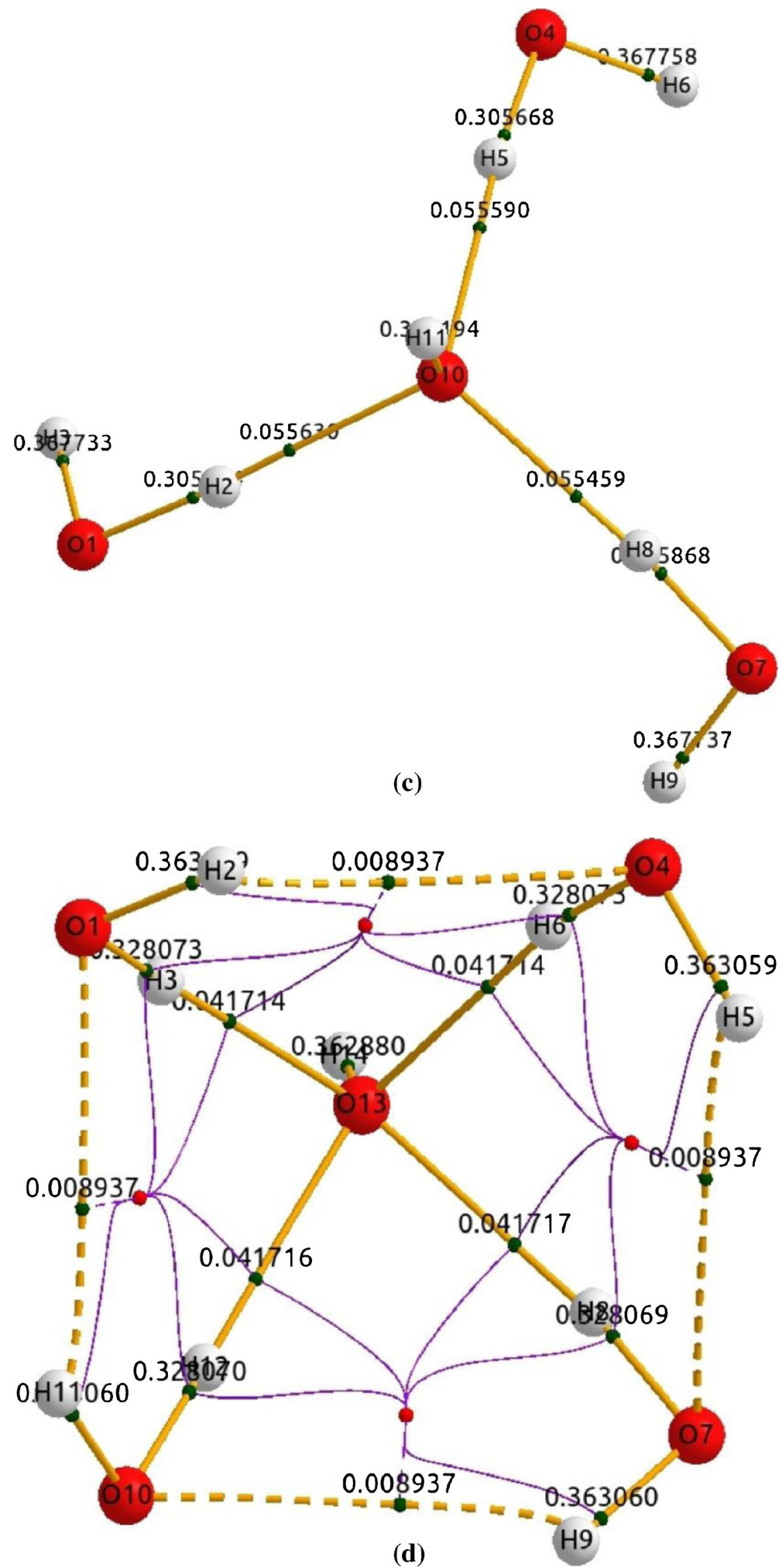

Figure 10. (cont.) 


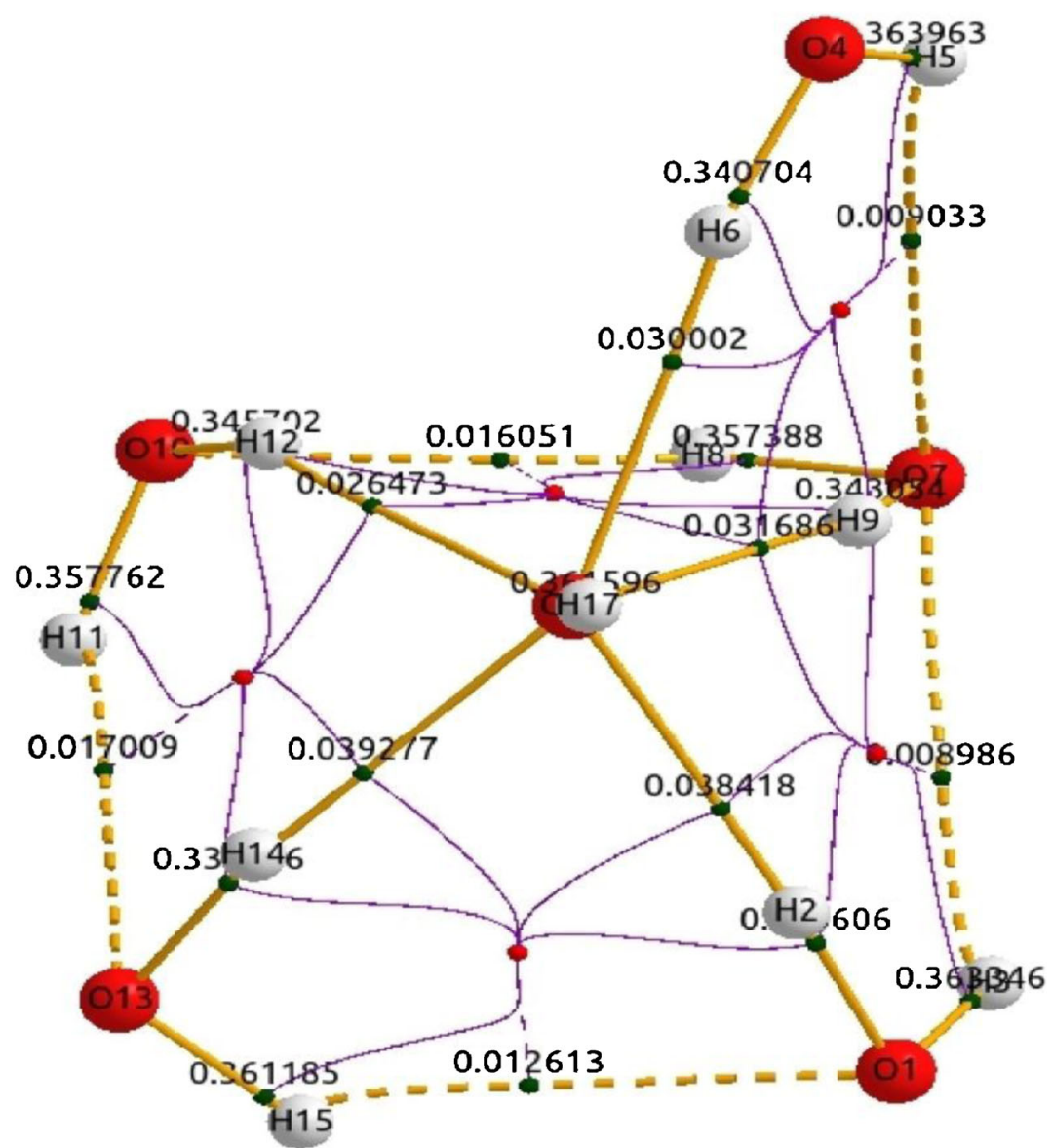

(e)

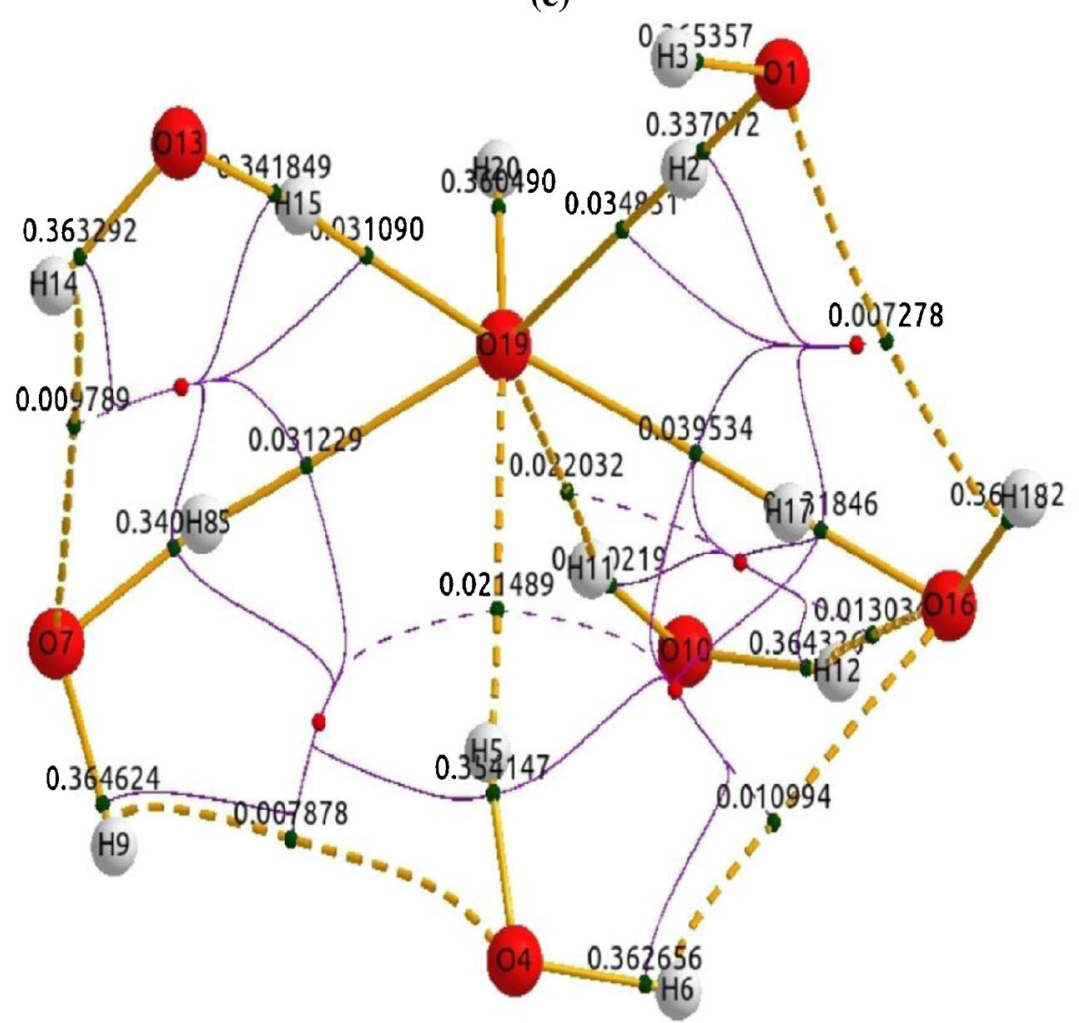

(f)

Figure 10. (cont.) 
Study of structure and spectroscopy of water-hydroxide

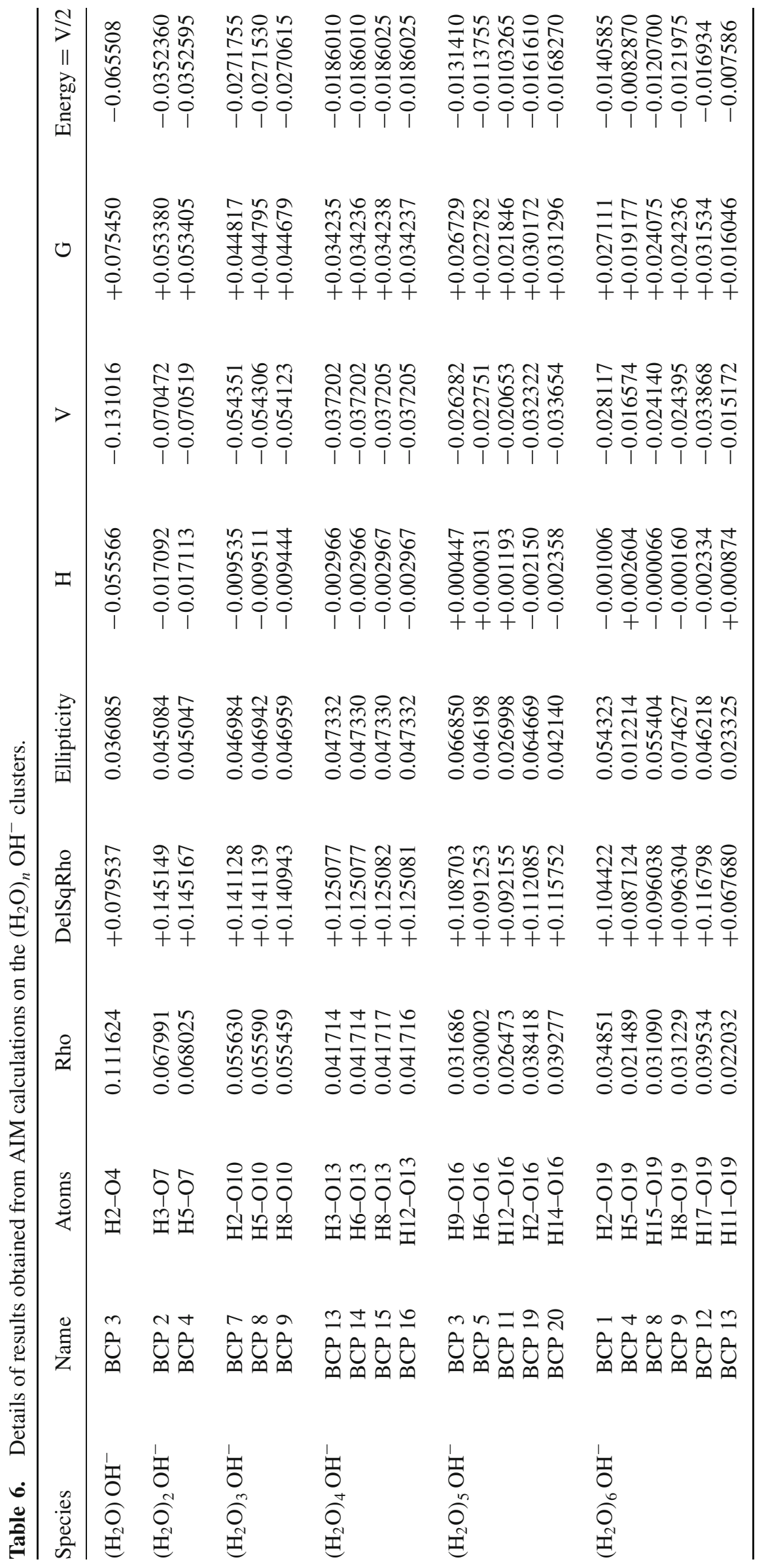


this is represented in table 6 . The table along with other necessary values contains the electron density as well as the H-bond energy for each and every $\mathrm{H}$-bond existing in all the cluster systems, that is $\left(\mathrm{H}_{2} \mathrm{O}\right)_{n} \mathrm{OH}^{-}$where $n=1-6$.

\section{Conclusion}

This study demonstrates the utility of a strategy based on combined SA and DFT to study structure and spectroscopic aspects of water-hydroxide ion clusters. The simple strategy discussed here can answer many questions related to spectral shits of different size clusters. We wish to extend our strategy to many fascinating systems in future communications.

\section{References}

1. Wang Y S, Chang H C, Jiang J C, Lin S H, Lee Y T and Chang H-C 1998 J. Am. Chem. Soc. 1208777

2. Klots C E and Compton R N 1978 J. Chem. Phys. 69 1644

3. Knapp M, Echt O, Kreisle D and Recknagel E $1986 \mathrm{~J}$. Chem. Phys. 85636

4. Schulz P A, Mead R D, Jones P L and Lineberger W C 1982 J. Chem. Phys. 771153

5. Owrutsky J C, Rosenbaum N H, Tack L M and Saykally R J 1985 J. Chem. Phys. 835338

6. Martin J M L 2001 Spectrochim. Acta. Part A 57875

7. Klots C E and Compton R N 1978 J. Chem. Phys. 69 1644

8. Mautner M 1986 J. Am. Chem. Soc. 1086189

9. Yang X and Castleman A W 1990 J. Phys. Chem. 94 8500

10. Schindler T, Berg C, Niedner-Schatteburg G and Bondybey V E 1995 J. Phys. Chem. 9912434

11. Robertson W H, Diken E G, Price E A, Shin J-W and Johnson M A 2003 Science 2991367

12. Price E A, Robertson W H, Diken E G, Weddle G H and Johnson M A 2002 Chem. Phys. Lett. 366412

13. Arshadi M and Kebarle P 1970 J. Phys. Chem. 741483

14. Mautner M and Speller C V 1986 J. Phys. Chem. 90 6616

15. Payzant J D, Yamdagni R and Kebarle P 1971 Can. J. Chem. 493308

16. Fraley P E and Rao K N 1969 J. Mol. Spectrosc. 29348

17. Buck U and Huisken F 2000 Chem. Rev. (Washington, D.C.) 1003863

18. Joseph R Roscioli, Eric G Diken, Mark A Johnson, Samantha Horvath and Anne B McCoy 2006 J. Phys. Chem. A 1104943

19. Jorgensen W L and Madura J D 1983 J. Am. Chem. Soc. 1051407

20. Jorgensen W L, Chandrasekhar J, Madura J D, Impey R W and Klein M L 1983 J. Chem. Phys. 79926

21. Jorgensen W L 1981 J. Am. Chem. Soc. 103335

22. Berendsen H J C, Postma J P M, vanGunsteren W F and Hermans J 1981 Intermolecular forces (ed.) Pullman B (Dordrecht: Reidel)
23. Berendsen H J C, Grigeria J R and Straatsma T P 1987 J. Phys. Chem. 916269

24. Wales D J and Hodges M P 1998 Chem. Phys. Lett. 286 65

25. Chaudhury P, Saha R and Bhattacharya S P 2001 Chem. Phys. 270277

26. Horn H W, Swope W C, Pitera J W, Madura J D, Dick T J, Hura G L and Head-Gordon T 2004 J. Chem. Phys. 1209665

27. Abascal J L F, Sanz E, Fernández R G and Vega C 2005 J. Chem. Phys. 122234511

28. Abascal J L F and Vega C 2005 J. Chem. Phys. 123 234505

29. Stillinger F H and Rahaman A 1974 J. Chem. Phys. 60 1545

30. Dyer K M, Perkyns J S, Stell G and Pettitt B M 2009 Mol. Phys. 107423

31. Mahoney M W and Jorgensen W L $2000 \mathrm{~J}$. Chem. Phys. 1128910

32. Rick S W 2004 J. Chem. Phys 1206085

33. Pliego J R and Riveros J M 2000 J. Chem. Phys. 112 4045

34. Newton M D and Ehrenson S 1971 J. Am. Chem. Soc. 934271

35. Ross B O, Kraemer W P and Diercksen G H F 1976 Theor. Chim. Acta $\mathbf{4 2} 77$

36. Szczesniak M M and Scheiner S 1982 J. Chem. Phys. 774586

37. Rohlfing C M, Allen L C, Cook C M and Schlegel H B 1983 J. Chem. Phys. 782498

38. Sapse M, Osorio L and Snyder G 1984 Int. J. Quantum Chem. 26223

39. Gao J, Garner D S and Jorgensen W L 1986 J. Am. Chem. Soc. 1084784

40. Del Bene J E 1988 J. Phys. Chem. 922874

41. Bankura A and Chandra A 2011 Chem. Phys. 38792

42. Bankura A and Chandra A 2012 Chem. Phys. 400154

43. Pratihar S and Chandra A 2011 J. Chem. Phys. 134 034302

44. Pratihar S and Chandra A 2010 J. Phys. Chem. 114 11869

45. Grimm A R, Bacskay G B and Haymet A D 1995 J. Mol. Phys. 86369

46. Tunon I, Rinaldi D, Ruiz-Lopez M F and Rivail J L 1995 J. Phys. Chem. 993798

47. Xantheas S S 1995 J. Am. Chem. Soc. 11710373

48. del Valle C P and Novoa J J 1997 Chem. Phys. Lett. 269401

49. Turki N, Milet A, Rahmouri A, Ouamerali O, Moszynski R, Kochanski E and Wormer P E S $1998 J$. Chem. Phys. 1097157

50. Lee H M, Tarkeshwar P and Kim K S 2004 J. Chem. Phys. 1214657

51. Wei D, Proynov E I, Milet A and Salahub D R $2000 \mathrm{~J}$. Phys. Chem. A 1042384

52. Neogi S G and Chaudhury P 2012 J. Comput. Chem. 33629

53. Masamura M 2002 J. Chem. Phys. 1175257

54. Masamura M 2001 Chem. Phys. Lett. 339279

55. Mejias J A and Lago S 2000 J. Chem. Phys. 1137306

56. Chaudhuri C, Wang Y S, Jiang J C, Lee Y T, Chang H C and Niedner-Schatteburg G 1161 Mol. Phys. 99.

57. Becke A D 1988 Phys. Rev. A 383098 
58. Lee C, Yang W and Parr R G 1988 Phys. Rev. B 37785

59. Pudzianowski A T 1995 J. Chem. Phys. 1028029

60. Pudzianowski A T 1996 J. Phys. Chem. 1004781

61. Tuckerman Mb E, Marx D, Klein M L and Parrinello M 1997 Science 275817

62. Lee H M, Suh S B, Lee J Y, Tarakeshwar P and Kim K S 2000 J. Chem. Phys. 1129759

63. Kim J, Majumdar D, Lee H M and Kim K S 1999 J. Chem. Phys. 1119128

64. Kim J and Kim K S 1998 J. Chem. Phys. 1095886

65. Kim K S, Mhin B J, Choi U S and Lee K 1992 J. Chem. Phys. 976649

66. Kim K S, Dupuis M, Lie G C and Clementi E 1986 Chem. Phys. Lett. 131451

67. Tsai C J and Jordan K D 1993 Chem. Phys. Lett. 213 181

68. Fowler J E and Schaefer III H F 1995 J. Am. Chem. Soc. 117446

69. Franken K A, Jalaie M and Dykstra C E 1992 Chem. Phys. Lett. 19859.

70. Burnham C J, Xantheas S S, Miller M A, Applegate B E and Miller R E 2002 J. Chem. Phys. 1171109

71. Lee H M, Lee S and Kim K S 2003 J. Chem. Phys. 119 187

72. Lee H M, Suh S B and Kim K S 2003 J. Chem. Phys. 1189981

73. Lee H M and Kim K S 2002 J. Chem. Phys. 117706

74. Suh S B, Lee H M, Kim J, Lee J Y and Kim K S 2000 J. Chem. Phys. 1135273

75. Kim J, Suh S B and Kim K S 1999 J. Chem. Phys. 111 10077

76. Kim J, Lee J Y, Oh K S, Park J M, Lee S and Kim K S 1999 Phys. Rev. A 59 R930

77. Novakovskaya Y V and Stepanov N F 2001 Chem. Phys. Lett. 344619

78. Kulkarni S A, Bartolotti L J and Pathak R K $2000 \mathrm{~J}$. Chem. Phys. 1132697

79. Tachikawa H, Lund A and Ogasawara M 1993 Can. J. Chem. 71118

80. Wang F and Jordan K D 2003 J. Chem. Phys. 119 11645

81. Lee S and Lee H M 2003 Bull. Korean Chem. Soc. 24 802

82. Khan A 2003 J. Chem. Phys. 1181684

83. Beyer M K, Fox B S, Reinhard B M and Bondybey V E 2001 J. Chem. Phys. 1159288

84. Lee H M, Suh S B and Kim K S 2003 J. Chem. Phys. 1197685

85. Lee H M, Kim D and Kim K S 2002 J. Chem. Phys. 1165509

86. Lee H M and Kim K S 2001 J. Chem. Phys. 1144461

87. Kim J, Lee H M, Suh S B, Majumdar D and Kim K S 2000 J. Chem. Phys. 1135259

88. Majumdar D, Kim J and Kim K S 2000 J. Chem. Phys. 112101.

89. Baik J, Kim J, Majumdar D and Kim K S 1999 J. Chem. Phys. 1109116

90. Markovich G, Giniger R, Levin M and Cheshnovsky O 1991 J. Chem. Phys. 959416

91. Markovich G, Pollack S, Giniger R and Cheshnovsky O 1994 J. Chem. Phys. 1019344

92. Combariza J E and Kestner N R 1994 J. Phys. Chem. 983513
93. Xantheas S S and Dunning T H 1994 J. Phys. Chem. 9813489

94. Combariza J E, Kestner N R and Jortner J 1994 J. Chem. Phys. 1002851

95. Chen H Y and Shew W S 2000 J. Am. Chem. Soc. 122 7534

96. Vanghn S J, Akhmatskaya E V, Vincent M A, Masters A J and Hillier I H 1999 J. Chem. Phys. 1104338

97. Kirkpatrick S, Gelatt C D and Vecchi M P 1983 Science 220671

98. Kirkpatrick S 1984 J. Stat. Phys. 34975

99. Car R and Parrinello M 1985 Phys. Rev. Lett. 552471

100. Yockel S, Seals J J and Wilson A K 2004 Chem. Phys. Lett. 393448

101. Yu B, Li B, Sun P, Chen T, Jin Q, Ding D and Shi A C 2005 J. Chem. Phys. 123234902

102. Pan L, Li J and Wang L S 2008 J. Chem. Phys. 129 024302

103. Xu M, Bacic Z and Hutson J M 2002 J. Chem. Phys. 1174777

104. Chaudhury P, Dutta P, Bandyopadhyay P, Sarkar P and Bhattaharyya S P 1996 Chem. Phys. Lett. 250238

105. Dutta P and Bhattaharyya S P 1990 Chem. Phys. Lett. 167309

106. Nandi S, Chaudhury P, Sharma R and Bhattaharyya S P 2008 J. Theor. Comp. Chem. 7977

107. Chaudhury P, Metzler R and Banik S K 2009 J. Phys. A 42335101

108. Guha S and Chaudhury P 2010 J. Mol. Struct. (THEOHEM) 94512

109. Guha S, Ray S and Chaudhury P 2011 Struct. Chem. 221007

110. Guha S, Mukherjee $\mathrm{N}$ and Chaudhury P 2012 Indian J. Phys. 86245

111. Merrill G N and Webb S P 2003 J. Phys. Chem. A107 7852

112. Masamura M 2002 J. Chem. Phys. 1175257

113. Hermansson K, Bopp P A, Spaangberg D, Pejov L, Bako I and Mitev P D 2011 Chem. Phys. Lett. 5141

114. Wales D J and Walsh T R 1997 J. Chem. Phys. 106 7193

115. Wales D J and Walsh T R 1996 J. Chem. Phys. 105 6957

116. Wales D J and Ohmine I 1993 J. Chem. Phys. 987257

117. Wales D J and Ohmine I 1993 J. Chem. Phys. 987245

118. Kiss P T and Baranyai A 2009 J. Chem. Phys. 131 204310

119. Bader R F W 1990 Atoms in molecules a quantum theory (Oxford, UK: Oxford University Press)

120. Koch U and Popelier P L A 1995 J. Phys. Chem. 99 9747

121. Mani D and Arunan E 2013 Chem. Phys. Chem. 14754

122. Raghavendra B and Arunan E 2008 Chem. Phys. Lett. 46737

123. Aiswaryalakshmi P, Mani D and Arunan E 2013 Inorg. Chem. 529153

124. Arunan E Desiraju G R, Klein R A, Sadlej J, Scheiner S, Alkorta I, Clary D C, Crabtree R H, Dannenberg J J, Hobza P, Kjaergaard H G, Legon A C, Mennucci B and Nesbitt D J 2011 Pure. Appl. Chem. 831619

125. Arunan E and Mani D 2013 Phys. Chem. Chem. Phys. 151537 